\title{
HISTORIOGRAFÍA MUSICAL DE LAS PARROQUIAS EN ESPAÑA: ESTADO DE LA CUESTIÓN
}

\author{
MUSICAL HISTORIOGRAPHY OF THE PARISHES IN SPAIN: \\ STATE OF THE ISSUE
}

\author{
Victoriano J. Pérez Mancilla \\ Universidad de Granada
}

\begin{abstract}
Resumen:
La mayoría de los trabajos realizados en España sobre música religiosa han tomado como objeto de estudio las catedrales y colegiatas, catalogando y transcribiendo obras, analizando los recursos musicales de los centros, la circulación de intérpretes entre ellos, la forma en que la economía eclesiástica afectó a su música o la evolución y aceptación de los diferentes estilos. Sin embargo, el estudio musical de las iglesias parroquiales no ha tenido la misma suerte, a pesar de que era en éstas donde se interpretaban las obras que escuchaba la mayoría de la población y que, en ocasiones, dispusieron de recursos materiales y humanos propios de templos con rango colegial e incluso catedralicio. Por ello, en este artículo se hace un recorrido a la historiografía musical española sobre parroquias, determinando el estado de la cuestión y favoreciendo así la realización de futuros estudios sobre el tema.
\end{abstract}

\section{Palabras clave:}

Parroquia, Música, Capilla de música, Órgano, Revista, Artículo, Libro

\begin{abstract}
:
Most of the studies carried out in Spain about religious music have taken the cathedrals and collegiate churches as their source of study, classifying and transcribing works, analyzing the musical resources of the centers, the circulation of interpreters among them, the way the ecclesiastical economy affected their music or the evolution and acceptance of the different styles. However, the musical study of the parish churches did not have the same success, although it was there where the works that most of the people listened were played and sometimes they had the material and human resources typical of churches with collegiate and even cathedral standing. So in this article it is covered the Spanish musical historiography about parish churches, determining the state of the topic and thus favoring future studies about the subject.
\end{abstract}

Key words:

Parish church, Music, Musical chapel, Organ, Journal, Article, Book 
Hasta hace poco tiempo los estudios históricos sobre la música española eran escasos y heterogéneos en lo que a su planteamiento se refería, lo que condujo a una exigua difusión y valoración de los mismos. Ajena a los triunfos mediáticos de los conciertos, la historiografía musical ha sido y es a menudo olvidada en España, incluso en las más importantes síntesis de la historia de nuestra cultura. A ello ha contribuido que muchos de los trabajos se limiten a la mera acumulación de datos y circunstancias relacionados con la música, obviando los métodos de la historiografía moderna que favorecen la recepción de dichos estudios en foros científicos más amplios.

Desde el siglo XIX, en España se reivindicó el pasado ilustre para ocultar las carencias de la vida musical en el país. Así, la narración heroica y la edición de las viejas glorias, sirvieron de sostén a una historiografía centrada en la música del Siglo de Oro, caso por ejemplo de la publicación Lyra SacroHispana $^{1}$. A pesar de ello, muchos tesoros musicales se han perdido, unas veces por el descuido y la poca valoración de los españoles y, otras, por la escasez de estudios musicológicos, las adversas circunstancias histórico-políticas o la falta de imprentas y bibliotecas.

Por fortuna, cada vez son más numerosos los trabajos de música en su doble vertiente profana y religiosa ${ }^{2}$. En cuanto a esta última, resulta paradójico que haya abundante bibliografía de diferentes capillas eclesiásticas, aunque no así de estudios generales sobre el funcionamiento de las mismas, su evolución o la forma en que incorporaron las novedades estilísticas a lo largo de los siglos; en consecuencia, esto dificulta establecer parámetros comparativos. Además, la historiografía de la música española, en su ámbito religioso, se ha centrado básicamente en el estudio de las catedrales y colegiatas. Sin embargo, el análisis musical de las iglesias con rango de parroquia y su relación con el contexto de los templos catedralicios y colegiales se ha desatendido ${ }^{3}$.

Como ya señalaba el profesor Antonio Gallego en 1978, "no se podrá abordar en su totalidad la historia social de la música española sin conocer estos modestos focos de producción y consumo que, por

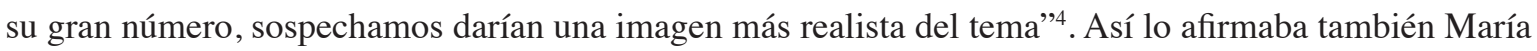
Gembero en 1998, para quien:

"es indudable que en las catedrales el culto y la música alcanzaban gran esplendor, y que en ellas se guarda buena parte de la música española anterior al siglo XIX. Sin embargo, nuestro conocimiento de la realidad musical del pasado será más rico si tiene en cuenta la actividad de esas otras instituciones no catedralicias, y especialmente las parroquias, en las que sonaba gran parte de la música que la población escuchaba a diario"s.

Por tanto, queda claro que se necesita establecer el estado de la cuestión sobre la música en las parroquias españolas, como base para la realización de estudios que expliquen el desarrollo de este arte en

1 ESLAVA Y ELIZONDO, 1852-1860, 10 vols. $68-135$.

2 Véase un compendio de la historiografía española sobre música eclesiástica en ROS-FÁBREGAS, 1 (Barcelona, 1998):

3 En otros países ya se realizaron hace años estudios generales sobre la música en sus parroquias. Véase el caso inglés en TEMPERLEY, 1979, 2 vols.

4 GALLEGO GALLEGO, 1/1-2 (Madrid, 1978): 243.

5 GEMBERO USTÁRROZ, 14/1 (Zaragoza, 1998): 269-270. 
las mismas y permitan valorar su papel en la producción e interpretación musical del país. Con este fin, seguidamente presentamos un detallado recorrido historiográfico en torno al tema parroquial.

\section{TRABAJOS INICIALES}

Entre los primeros trabajos que ofrecían datos sobre la música en parroquias hay que citar varios Diccionarios. El primero de ellos es el Geográfico-Estadístico-Histórico de España y sus posesiones de Ultramar, obra de Pascual Madoz publicada entre 1845 y $1850^{6}$. En concreto, este Diccionario recogía diversa información de cada localidad española, incluyendo la plantilla musical de sus iglesias en la época -desde las que contaban con organista, como por ejemplo la de San Lorenzo de Busot, hasta las que disponían de una capilla completa, caso de la de Santa María de Huéscar-.

Otro Diccionario interesante fue el Técnico, histórico y biográfico de la música, publicado por José Parada en 1868, puesto que ofrecía datos puntuales sobre la actividad de algunos músicos en parroquias como la de San Andrés de Valencia- ${ }^{7}$. Ese mismo año, 1868, Baltasar Saldoni también comenzó a publicar su Diccionario biográfico-bibliográfico de efemérides de músicos españoles, obra que volvía a recoger noticias de músicos al servicio de iglesias parroquiales -sirva como ejemplo la de Santa María del Mar de Barcelona- ${ }^{8}$.

En la misma línea, Felipe Pedrell publicó en 1897 parte de otro Diccionario con información puntual sobre intérpretes de parroquias -caso de la de San Salvador de Concentaina-, obra titulada: Diccionario biográfico y bibliográfico de músicos y escritores de música españoles, portugueses e hispano-americanos, antiguos y modernos ${ }^{9}$. Además, en esta misma época, concretamente desde 1896 hasta 1899, Pedrell también dirigió la revista La música religiosa en España, donde recogía tanto noticias de la actividad musical que se desarrollaba en el país, como artículos de música histórica y contemporánea. Entre estos últimos destacamos los que versaban sobre parroquias, como el de Antonio Noguera de julio de 1898 sobre "La capella de Manacor", conjunto vocal fundado sólo unos años antes ${ }^{10}$.

Ya en el siglo XX, en 1903, José Ruiz publicó un nuevo Diccionario que llevaba por título La música en Valencia. Diccionario biográfico y crítico, donde al igual que en sus antecesores se incluían voces de músicos que ejercieron en iglesias parroquiales, en este caso levantinas -como la de Santa María de Onteniente o la de Santa Catalina de Alzira- ${ }^{11}$. Además, de las primeras décadas del siglo XX también hay que hacer mención a algunos artículos de la Revista Musical Catalana que trataban el tema de la música parroquial, recogidos en la sección "La música a Catalunya. Aplega de materials per contribuir a sa his-

\footnotetext{
6 MADOZ IBÁÑEZ, 1845-1850, 16 vols.

7 PARADA Y BARRETO, 1868.

8 SALDONI Y REMENDO, 1868-1881, 4 vols.

9 PEDRELL SABATÉ, 1897.

10 NOGUERA, 31 (Madrid, 1898): 97-105.

11 RUIZ DE LIHORY, 1903.
} 
toria”. Así, por ejemplo, en 1915, Fortià Solà escribió uno donde transcribía un documento de 1444 sobre el primitivo órgano de la parroquia de Santa Coloma de Centelles ${ }^{12}$.

\section{LA DÉCADA DE 1940}

Más cercano a la mitad del siglo XX fue el libro de Andrés Araiz dedicado a la Historia de la música religiosa en España, en concreto de $1942^{13}$. En esta obra se analizaban principalmente los aspectos técnicos utilizados en dicha música a lo largo de los siglos, pero al final de la monografía quedaban recogidas breves reseñas de organistas y maestros de capilla españoles de los siglos XVII al XIX, entre ellas las de algunos que sirvieron en parroquias.

De la década de los cuarenta también fueron los primeros artículos de la revista Anuario Musical, entre los que se encontraban varios con información sobre parroquiales. Así, en el número I de la revista, en 1946, Francisco de Paula Baldelló publicó un artículo titulado: "Órganos y organeros en Barcelona. Siglos XIII-XIX"14. En él ofrecía datos sobre órganos históricos de las iglesias barcelonesas de Santa María de Sans, Santa María del Mar o Nuestra Señora del Pino. Tras ello, estudiaba la figura y la obra de diversos organeros que trabajaron en Barcelona, incluyendo datos de diferentes parroquias.

Un año más tarde, en 1947, la revista Anuario Musical incluyó el artículo de Josep Maria Madurell titulado "Documentos para la historia del órgano en España", un trabajo que se limitaba a transcribir diversas fuentes primarias sobre órganos barceloneses de los siglos XV al XVIII ${ }^{15}$. Lo interesante es que entre los documentos transcritos se hallaban algunos de parroquias, como por ejemplo el relativo a los órganos de la iglesia de San Jaime -1529- o el de las oposiciones a la plaza de organista del templo de los Santos Justo y Pastor -1672-. Además, en 1948 y 1949 Madurell volvió a publicar artículos en Anuario Musical, titulados: "Documentos para la historia de maestros de capilla, infantes de coro, maestros de música y danza y ministriles en Barcelona. Siglos XIV-XVIII"; y "Documentos para la historia de maestros de capilla, organistas, órganos, organeros, músicos e instrumentos. Siglos XIV-XVIII"16. Se trataba de dos trabajos con la misma metodología que el de 1947 sobre órganos. Así, en éstos de 1948 y 1949 se recogía la transcripción de fuentes primarias, algunas de ellas relativas a parroquias, como los documentos de 1667 y 1699 sobre la elección de maestros de capilla en las iglesias de San Miguel Arcángel y Santa María del Mar, respectivamente.

En el número de Anuario Musical correspondiente a 1949, también se recogía un artículo de Francisco de Paula Baldelló sobre "Los órganos de la basílica parroquial de Nuestra Señora de los Reyes (Pino), de Barcelona”, un templo que no fue elevado a basílica hasta $1925^{17}$. En cuanto al tema musical, el estudio

12 SOLÀ, 136 (Barcelona, 1915): 102-103.

13 ARAIZ MARTÍNEZ, 1942.

14 BALDELLÓ BENOSA, 1 (Barcelona, 1946): 195-237.

15 MADURELL, 2 (Barcelona, 1947): 203-216.

16 MADURELL, 3 (Barcelona, 1948): 213-234; 4 (Barcelona, 1949): 193-220.

17 BALDELLÓ BENOSA, 4 (Barcelona, 1949): 155-179. 
recogía las primeras noticias sobre un órgano en la iglesia, del siglo $\mathrm{XV}$, presentando después los datos históricos y técnicos del resto de instrumentos construidos hasta finales del XIX.

\section{LA DÉCADA DE 1950}

Dos años después del estudio sobre la parroquia de los Reyes, en 1951, Josep Maria Madurell volvió a incluir un artículo en Anuario Musical transcribiendo diversas fuentes sobre la música religiosa en Barcelona, aunque también presentaba datos sobre organeros y sus obras. El título del artículo era: "Documentos para la historia de los maestros de capilla, cantores, organistas, órganos y organeros. Siglos XIV-XVIII"18. Sirva como ejemplo de los textos transcritos sobre parroquias el del pago en 1692 al maestro de capilla de la iglesia barcelonesa de Santa María del Pino, Benedicto Buscarons, por interpretar música en un entierro.

En 1951 también se publicó el libro de José Antonio de Donostia sobre la Música y músicos en el País Vasco, presentando algunos datos en torno a la música parroquial como el nombre de maestros de capilla y organeros -siglos XVI-XIX-19. Además, este mismo autor escribió en 1955 un artículo para Anuario Musical con el título: "El órgano de Tolosa (Guipúzcoa), del año 1686”20. Este trabajo transcribía diversos documentos relativos a la construcción de un órgano en la parroquia de Santa María de la villa tolosana, instrumento que costeó el concejo de la localidad por ser patrono de dicho templo.

\section{LA DÉCADA DE 1960}

Uno de los primeros trabajos más significativos sobre una iglesia española con rango de parroquia fue el artículo de Francisco de Paula Baldelló titulado "La música en la basílica parroquial de Santa María del Mar, de Barcelona", que vio la luz en 1962 en la revista Anuario Musical ${ }^{21}$. Esta fecha es temprana, ya que el primer estudio que marcó el despegue de la musicología con tema religioso en España fue el de 1961 de Robert Stevenson Spanish Cathedral Music in the Golden Age, mientras que la investigación pionera que analizaba individualmente el funcionamiento de una capilla de música fue el que publicó José López-Calo en 1963, sobre La música en la catedral de Granada en el siglo XVI22.

El artículo de Francisco de Paula Baldelló relativo a la parroquia de Santa María del Mar de Barcelona comenzaba con una introducción histórica al templo, que alcanzó el título de basílica menor en 1923 y fue administrado por una comisión o Junta de Obra -en la que estaban representados los clérigos

18 MADURELL, 6 (Barcelona, 1951): 205-255.

19 DONOSTIA, 1951.

20 DONOSTIA, 10 (Barcelona, 1955): 121-136.

21 BALDELLÓ BENOSA, 17 (Barcelona, 1962): 209-241.

22 STEVENSON, 1961. LÓPEZ-CALO, 1963, 2 vols. 
del templo, los feligreses y otras instituciones locales como los gremios-. A continuación se recogían los inventarios que se hicieron del archivo musical de la iglesia desde el siglo XVI, un fondo destruido durante la Guerra Civil. Con ello se pasaba a estudiar cada uno de los organistas localizados desde el siglo XV hasta el XX, a lo que seguía un compendio de las obligaciones y derechos de los maestros de capilla junto a la presentación de diversos datos sobre cada uno de estos personajes -siglos XVI-XX-. Después se presentaba un epígrafe sobre los cantores de la iglesia barcelonesa -incluyendo a los de canto llano y a los de órgano-, tras lo que se insertaba un nuevo apartado en torno a los instrumentos e instrumentistas de la capilla musical. Por último, Francisco de Paula Baldelló dedicaba un epígrafe a los órganos construidos en la iglesia de Santa María del Mar y a los organeros encargados de los mismos -siglos XIV-XX-.

El completo artículo de Baldelló auguraba el desarrollo de una línea de investigación sobre los templos parroquiales. Así fue, ya que sólo dos años después, en 1964, apareció en la revista Anuario Musical un nuevo artículo titulado "Fundacions litúrgiques a Santa Maria de Mataró", de Josep Maria Madurell²3. En él se estudiaba la institución -de 1689- de diversas celebraciones litúrgicas en la citada parroquia mataronense -templo basilical desde 1928-, fundaciones privadas de un clérigo en las que la música, sobre todo el canto llano, jugaba un papel destacado.

Otro artículo de Anuario Musical sobre parroquias fue el de Manuel Milián de 1968 con la "Historia del órgano de Santa María la Mayor de Morella", donde, tras hacer una introducción a la iglesia -erigida basílica menor en el siglo XX-, se presentaba el devenir de los órganos construidos en la misma desde el siglo XV hasta el $\mathrm{XX}^{24}$.

Ya en 1969 surgió un nuevo trabajo centrado en el estudio musical de una parroquia, concretamente el artículo que publicó José María Soler en la Revista del Instituto de Estudios Alicantinos con el título: "La antigua capilla musical de Santiago de Villena"25. En primer lugar, el autor exponía cómo en el siglo XVI el templo ya contaba con sochantre para regir el coro de los oficios, organista y capilla de música, esta última formada por un maestro, cantores y un intérprete de bajón. Posteriormente se estudiaba la evolución de dicha capilla hasta el siglo XVIII, a lo que seguían epígrafes sobre los libros de música con los que contó la iglesia de Santiago en esta misma cronología, los órganos, los infantillos o los ministriles.

\section{LA DÉCADA DE 1970}

En 1970 se publicó una monografía con información sobre la música en parroquias, trabajo de Francesc Civil titulado: El fet musical a les comarques gironines en el lapse de temps 1800-1936 ${ }^{26}$. En concreto, la segunda parte del libro estudiaba la actividad musical y los principales protagonistas de la misma en una treintena de localidades gerundenses, ofreciendo multitud de datos sobre parroquias. Además, en el

\footnotetext{
23 MADURELL, 19 (Barcelona, 1964): 11-117.

24 MILIÁN MESTRE, 21 (Barcelona, 1966-1968-): 169-187.

25 SOLER GARCÍA, 2 (Alicante, 1969): 7-36.

26 CIVIL CASTELLVÍ, 1970.
} 
caso de algunos centros, la información se remontaba incluso a una cronología anterior a la del título del trabajo, situando, por ejemplo, maestros de capilla en las parroquias de Sant Esteve de Olot, Sant Genís de Torroella de Montgrí y Santa Maria de La Bisbal d'Empordá en 1651, 1652 y 1694 respectivamente.

También de la década de 1970, en concreto de 1971, fue el artículo que incluyó Pedro Calahorra en la revista Anuario Musical con el título "Cien años de la historia del órgano de San Pablo de Zaragoza (1742-1826)", donde, a pesar del encabezamiento, detallaba la historia de dicho instrumento parroquial desde la segunda mitad del siglo XVI'27.

Dos años más tarde de este estudio, en 1973, Francesc Civil volvió a publicar un trabajo de música en parroquias, concretamente sobre los "Mestres de la capella de cant i organistes de la parroquia de Sant Esteve de la vila d'Olot, segles XVII i XVIII”28. En él se hacía un relato histórico de los citados maestros de canto y organistas de la iglesia olotina de Sant Esteve -templo que disponía de una cabildo de beneficiados-, retomando bastantes datos aparecidos ya en el libro de la música gerundense escrito por el autor en 1970 .

Ya en 1976, Francesc Bonastre publicó en Anuario Musical el artículo: "El órgano de Santa María de Montblanc y sus organistas durante los siglos XVII-XVIII"29. Se trataba de un estudio descriptivo e histórico sobre dicho instrumento, comenzado a construirse en 1607 -con el patrocinio del ayuntamiento de la villa tarraconense- y que tras diversas vicisitudes aún hoy se conserva. Además, en este trabajo se recogían los datos sobre los personajes que ocuparon la plaza de órgano en la iglesia durante el periodo estudiado, plaza que llevaba aneja la del magisterio de capilla y que era retribuida por el ayuntamiento de Montblanc, aunque la comunidad de clérigos de Santa María también pagaba a los músicos por asistir a los cultos.

Tras este artículo, en 1978, apareció otro sobre una parroquial titulado "Un siglo de música en Valdemoro (1582-1692)", del que era responsable Antonio Gallego y que fue publicado en la Revista de Musicología $a^{30}$. En él, su autor presentaba los inventarios de instrumentos y de libros de música -tanto de canto llano como de órgano- que se hicieron en la iglesia parroquial de Nuestra Señora de la Asunción de Valdemoro entre los siglos XVI y XVII. Con ello pasaba a exponer de forma breve las diferentes plazas musicales creadas en el templo -maestro de capilla, cantores, ministriles y sacristán-organista- y a dar el nombre de algunos de sus propietarios, con noticias puntuales sobre los emolumentos que recibían.

Un año después del trabajo de Antonio Gallego, en 1979, se publicó en el Butlletí de la Societat Catalana de Musicologia el artículo de Josep Maria Gregori sobre "L'orgue de Santa Maria d'Igualada i l'obra restauradora dels orgueners Josep Boscà i Antoni Boscà al segle XVIII", estudio que presentaba y analizaba diversas fuentes primarias sobre la actuación de estos dos personajes en el instrumento parroquial igualadî ${ }^{31}$.

27 CALAHORRA MARTÍNEZ, 25 (Barcelona, 1970-1971-): 143-167.

28 CIVIL CASTELLVÍ, 1973: 103-110.

29 BONASTRE I BERTRÁN, 28-29 (Barcelona, 1973-1974-1976-): 243-267.

30 GALLEGO GALLEGO, 1/1-2 (Madrid, 1978): 243-253.

31 GREGORI I CIFRÉ, 1 (Barcelona, 1979): 75-93. 
Para finalizar con la década de los setenta, cabe hacer mención a la monografía de Vicente PérezJorge titulada La música en Onteniente, de $1979^{32}$. En ella se trataba de los organistas y maestros de capilla de la iglesia ontiñentina de Santa María -siglos XVI-XIX-, ofreciendo también listados de cantores y ministriles. Además, el autor estudiaba los organistas de las iglesias de San Carlos y el Colegio de la Concepción de Onteniente, pasando después a ofrecer una gran cantidad de datos sobre los órganos construidos desde el siglo XVI no sólo en los templos citados, sino también en el resto de centros religiosos ontiñentinos.

\section{LA DÉCADA DE 1980}

Después del libro de Pérez-Jorge, en 1980, Juan Cruz Labeaga publicó en la revista Príncipe de Viana el artículo: "La música en la parroquia de Santa María de Viana (Navarra), siglos XVI y XVII"33 . Éste era un amplio trabajo que presentaba las noticias musicales sobre la parroquia vianesa de Santa María recogidas en las disposiciones episcopales de la época. Tras ello se ofrecían datos de los órganos con los que contó el templo y de los organeros encargados de su construcción, reforma o afinación. Posteriormente se hacía lo propio con la capilla de música que empezó a fraguarse a finales del siglo XVI, pero que no se constituyó hasta principios del XVII. Además, el autor también transcribía las referencias sobre fiestas organizadas por la parroquia vianesa con intervención de músicos y danzantes, haciendo después lo mismo con los inventarios de libros y cuadernos de música. Por último, en el artículo aparecían listados de los integrantes de la capilla musical y sus emolumentos.

En 1980 también se publicaron varios números de la revista Órganos del País Valenciano dedicados a instrumentos históricos de parroquias. Así, por ejemplo, José María Doñate presentó un breve trabajo sobre el "Órgano de Villarreal", con datos sobre los sucesivos instrumentos de la parroquia villarrealense de San Jaime -siglos XIV-XX-, intercalando también noticias de los intérpretes de los mismos ${ }^{34}$. Otro ejemplo de artículo de tema parroquial en la revista fue el de Serafín Sorribes sobre el "Órgano de Cinctorres (Castellón)", donde presentaba igualmente la historia de los órganos de la iglesia cinctorrana de San Pedro-siglos XVII-XX-, insertando también referencias a los intérpretes ${ }^{35}$.

Un año más tarde de estos trabajos, en 1981, se publicaron las actas del I Congreso Nacional de Musicología, incluyendo el texto de dos ponencias que versaban sobre música en parroquias. La primera de ellas se titulaba "L'orgue de Sarreal de 1788", un trabajo de Francesc Bonastre donde describía técnicamente el citado instrumento de la parroquia de Santa María sarralense, estudiaba la figura de su constructor-Josep Cases- y transcribía el contrato original para la realización del mismo, suscrito entre

32 PÉREZ-JORGE, 1979, 3 vols.

33 LABEAGA MENDIOLA, 158-159 (Pamplona, 1980): 203-250.

34 DOÑATE SEBASTIÁ, 7 (Valencia, 1980): 13-21.

35 SORRIBES CARCELLER, 12 (Valencia, 1980): 2-24. 
el organero y el ayuntamiento de Sarreal -institución esta última patrocinadora de la obra- ${ }^{36}$. Por su parte, la segunda ponencia sobre el tema parroquial se titulaba "Oposiciones al cargo de organista en Sueca (Valencia) a la muerte de Vicente Hervás (1745)”, un estudio de Vicente Ros en el que se recogían datos sobre la oposición de 1745 convocada por el ayuntamiento de Sueca, patrono de la iglesia de San Pedro de la localidad, para cubrir la plaza de organista de dicho templo ${ }^{37}$.

En 1981 también se publicó el artículo "Els organistes de Santa Maria d'Igualada en el período 1689-1738: documents per a la seva historia”, aparecido en la revista Recerca Musicològica y del que era autor Josep Maria Gregori ${ }^{38}$. En efecto, el trabajo ofrecía todos los datos obtenidos de cada uno de los organistas que, con el patrocinio del concejo de la villa y la aprobación del cabildo beneficial que regía el templo, ejercieron en la iglesia igualadina durante el periodo señalado. Además, el estudio sirvió de complemento al que ya escribiese este mismo autor en 1979 sobre el órgano de Santa María de Igualada en el siglo XVIII.

En el número de Recerca Musicològica de 1981 también se recogían otros dos artículos sobre música parroquial. El primero era de Francesc Bonastre y se titulaba: "Josep Carcoler (†1776): noticia biográfica i compositiva" 39 . Lo más interesante de este trabajo respecto al tema de las parroquias fue la inclusión de un epígrafe sobre el magisterio del músico catalán en la iglesia de Sant Esteve de Olot, además de catalogar la obra compositiva del mismo. Por su parte, el segundo artículo, de Assumpció Heras y titulado "La instauració del magisteri de cant de Sant Pere de Figueres a les primeries del segle XVII", estudiaba un documento de 1602 por el que se fundaba un beneficio para el magisterio de canto de la citada iglesia, con el patrocinio del concejo de la villa figuerense ${ }^{40}$.

Otro artículo de 1981 fue el de Ismael Fernández de la Cuesta publicado en la Revista de Musicología, donde analizaba "Los cantos monódicos en el «Misterio de Elche»”, es decir, el drama litúrgico representado anualmente en la iglesia ilicitana de Santa María sobre la Asunción de la Virgen ${ }^{41}$. Un año más tarde, en 1982, Joan Maria Thomàs y Joan Parets publicaron una Breu historia musical de les Illes Balears, recogiendo un epígrafe con cierta información sobre los órganos, organeros y organistas de los templos isleños a lo largo de los siglos, algunos de ellos parroquias ${ }^{42}$.

En 1982 también comenzó a publicarse una revista llamada Cabanilles, que recogía bastantes artículos sobre la música en parroquias y, concretamente, sobre sus órganos. Así, en el número I, de 1982, se presentó el artículo de José María Soler sobre "El antiguo órgano de la iglesia parroquial de Sax (Alicante)", informando de la escritura que en 1686 firmaron los beneficiados y alcaldes de la villa con el organero Thomás Juan, para la construcción del citado instrumento ${ }^{43}$. A éste le acompañaba otro artículo

36 BONASTRE I BERTRÁN, 1981a: 267-275.

37 ROS PÉREZ, 1981: 363-364.

38 GREGORI I CIFRÉ, 1 (Bellaterra, 1981): 95-112.

39 BONASTRE I BERTRÁN, 1 (Bellaterra, 1981b): 113-150.

40 HERAS I TRIAS, 1 (Bellaterra, 1981): 203-212.

41 FERNÁNDEZ DE LA CUESTA, 4/1 (Madrid, 1981): 41-49.

42 THOMÀS I SABATER y PARETS Y SERRA, 1982.

43 SOLER GARCÍA, 1 (Valencia, 1982): 35-36. 
de Miguel Alepuz y Carlos Beneito sobre "El órgano de Ribesalbes", donde se reproducía un documento de 1852 relativo a la construcción del instrumento en la parroquia ribesalbense de San Cristóbal, por parte del organero Miguel Alcarria ${ }^{44}$.

En 1982 aparecieron igualmente en Cabanilles otros dos artículos sobre el tema parroquial. El primero de ellos, de Fernando Pingarrón y titulado "La música en la parroquia de San Martín de Valencia (ss. XVI-XX)", comenzaba con una introducción histórica al centro objeto de estudio, que daba paso a una detallada exposición de los datos obtenidos sobre los órganos del templo desde el siglo XIV hasta el $\mathrm{XX}^{45}$. Tras ésta, Fernando Pingarrón también dedicaba un epígrafe a los organistas de San Martín, con datos que se remontaban al siglo XVI. Además, el artículo se completaba con el estudio de los personajes que ejercieron tanto la sochantría como el magisterio de capilla de la iglesia, plazas que se remontaban al menos al siglo XVII. Por su parte, el segundo artículo sobre el tema parroquial fue el de Amparo Ranch en torno a los "Órganos y organistas de la villa de Ayora", donde ofrecía la historia de los instrumentos que se construyeron en las iglesias ayorinas de Santa María la Mayor y Nuestra Señora de la Asunción -siglos XVI-XX- y datos sobre sus tañedores ${ }^{46}$.

En 1983 la revista Cabanilles volvió a recoger algunos trabajos sobre el tema parroquial, como el de Josep Nicolau sobre los “Órganos de la parroquia de los Santos Juanes» de Valencia y el de Vicent Olmos y Antoni López en torno a los "Órganos y organistas de Catarroja (Valencia)" ${ }^{4}$. En el primero de ellos se estudiaban los órganos de la iglesia de los Santos Juanes desde el siglo XV, mientras que en el segundo se hacía lo propio con instrumentos construidos en el templo catarrojense de San Cosme y San Damián desde el XVII. Además, en este segundo artículo se aportaban algunos datos sobre organistas.

De 1983 también fue el trabajo de José Sánchez sobre "El órgano y los organistas de la Iglesia Mayor de Montblanc", recogido en la revista Recerca Musicològica ${ }^{48}$. Este artículo completaba el que en 1976 publicó Francesc Bonastre sobre el mismo tema, ofreciendo nuevos datos del órgano de la iglesia montblanquina en los siglos XVII-XVIII y ampliando la nómina de intérpretes hasta el siglo XX.

En 1984 la revista Cabanilles publicó nuevamente artículos sobre parroquias: el primero, de Vicent Sala, hacía un breve estudio sobre "L'orgue de l'esglèsia parroquial de Sant Pere Apòstol de Novelda" desde el siglo XVII hasta comienzos del XX, templo patrocinado por el concejo de la localidad alicantina $^{49}$; el segundo artículo, "Dades sobre un orgue de Nicolau de Salanova a l'esglèsia parroquial de la Santa Creu de Valencia a primeries del segle XVIII", de Fernando Pingarrón, estudiaba el instrumento construido en 1722 por el citado organero y también ofrecía noticias sobre los organistas del siglo XVIII ${ }^{50}$; el tercer trabajo, de Rafael Torres y titulado "La iglesia, el órgano y la música en Villafamés (Castellón)”, se dedicaba a los órganos de la iglesia de Nuestra Señora de la Asunción de la localidad castellonense desde

44 ALEPUZ y BENEITO, 1 (Valencia, 1982): 30-31.

45 PINGARRÓN SECO, 2-3 (Valencia, 1982): 6-86.

46 RANCH SALES, 4 (Valencia, 1982): 2-35.

47 NICOLAU BAUZÁ, 7 (Valencia, 1983): 5-30. OLMOS I TAMARIT y LÓPEZ I QUILES, 8 (Valencia, 1983): 2-33.

48 SÁNCHEZ REAL, 3 (Bellaterra, 1983): 81-136.

49 SALA CAÑLLLAS, 9 (Valencia, 1984): 3-7.

50 PINGARRÓN SECO, 9 (Valencia, 1984): 8-32. 
comienzos del siglo XVII" sical de la parroquia de San Martín de Valencia”, presentaba un documento de 1755 por el que se jubilaba al maestro de capilla Luis López ${ }^{52}$.

Otro estudio destacado de 1984 fue la monografía de María del Pilar Barrios con la Historia de la música en Cáceres, 1590-1750, un trabajo dividido en diferentes partes ${ }^{53}$. La primera de ellas introducía el tema de estudio, centrándose en la capilla musical con la que contó la iglesia de Santa María de Cáceres durante el periodo cronológico elegido. Ya en la segunda parte se establecían las funciones de los maestros de capilla, cantores y ministriles del templo cacereño, ofreciendo el nombre y diversos datos sobre la actividad musical de los mismos. A continuación se hacía lo propio con los organistas, pero no sólo con los de la iglesia de Santa María, sino también con los de las otras tres parroquias de Cáceres -San Mateo, San Juan y Santiago-; además, se estudiaba la figura de los organeros que trabajaron en los templos cacereños y las cuestiones técnicas de los instrumentos construidos.

En 1984 también se publicaron las Actas del IX Congreso de Estudios Vascos, recogiendo el texto de una brevísima comunicación de Juan Cruz Labeaga sobre las "Diversiones públicas en las fiestas religiosas [del] siglo XVIII de la parroquia de San Pedro de Viana (Navarra)" "54. Sin embargo, resultó mucho más interesante el artículo de 1985 de este mismo autor incluido en la revista Cuadernos de SecciónMúsica y que llevaba por título: "La música en la parroquia de San Pedro de Viana (Navarra)" 55 . Al igual que el trabajo publicado por dicho investigador en 1980 sobre el templo vianés de Santa María, éste de la iglesia de San Pedro era amplio. No obstante, la secuencia cronológica estudiada en 1985 fue mayor que la de 1980, concretamente desde las primeras referencias musicales sobre San Pedro -del último tercio del siglo XVI- hasta el hundimiento del templo en 1844 y su desaparición jurídica en 1869. En cuanto a los epígrafes del trabajo, detallamos que el primero de ellos era el más amplio y se dedicaba a los órganos de la iglesia y a los organeros que intervinieron en los mismos. Posteriormente se introducía otro apartado sobre los músicos con los que contó la iglesia a lo largo de los siglos. Así, el autor exponía cómo el templo dispuso siempre de organista y que éste asumió también en una primera época las labores de sochantre. En realidad, la iglesia de Santa Pedro de Viana no tuvo una capilla de música como su vecina de Santa María, sino que sólo dispuso de organista, de sochantre y, esporádicamente, de algunos cantores e instrumentistas. Tras este estudio de los intérpretes, Juan Cruz Labeaga dedicaba un breve epígrafe a las disposiciones episcopales que contenían datos sobre la actividad musical en San Pedro, otro a transcribir noticias de las principales fiestas con intervención musical celebradas en la parroquia -retomando la comunicación del autor sobre el mismo tema recogida en las Actas del IX Congreso de Estudios Vascos- y, por último, un espacio con los inventarios de libros de música realizados a lo largo de los siglos.

51 TORRES CAROT, 12 (Valencia, 1984): 4-10.

52 VILLALMANZO CAMENO, 12 (Valencia, 1984): 11-14, 23.

53 BARRIOS MANZANO, 1984.

54 LABEAGA MENDIOLA, 1984: 452-453.

55 LABEAGA MENDIOLA, 2 (San Sebastián, 1985): 7-77. 
Sin embargo, no fue éste el único artículo sobre parroquiales recogido en la revista Cuadernos de Sección-Música de 1985. Así, la publicación también incluyó un trabajo de Claudio Zudaire con "Notas sobre órganos y organistas de Guipúzcoa en el siglo XVII", un compendio de episodios musicales referidos a las parroquias de Segura, Usurbil, Rentería y San Sebastián ${ }^{56}$. De este modo, Zudaire estudiaba la intervención de diferentes organeros en los templos y los instrumentos construidos -muchas veces gracias al patronazgo de los concejos locales-, además del régimen jurídico, las obligaciones o el salario de los músicos encargados de tañerlos. Igualmente, la revista Cuadernos de Sección-Música de 1985 insertaba un trabajo titulado "Catálogo de los fondos musicales antiguos de Laguardia (Álava)", de Jon Bagüés, donde se hacía dicha catalogación de las obras, pero también se situaba una capilla de música en la iglesia de Santa María de los Reyes de la localidad alavesa -siglos XVII-XIX-, grupo que nació y se mantuvo gracias a la obra pía de uno de los parroquianos; además, en el trabajo se aportaban noticias sobre maestros de capilla ${ }^{57}$.

En 1985 también se publicó el artículo "Órganos y organistas de Alzira” en la revista Cabanilles, de Vicente Alonso ${ }^{58}$. Éste comenzaba con una introducción geográfica e histórica a la villa valenciana, pasando después a describir artísticamente las iglesias de la localidad, es decir, las de Santa María y Santa Catalina, ambas patrocinadas por el concejo civil. Tras ello, el autor del trabajo presentaba un estudio de los órganos, organistas y organeros que intervinieron en dichos templos desde el siglo XV hasta el XX, con especial atención al de Santa Catalina. Además, Vicente Alonso ofrecía algunos datos sobre la capilla de música que actuó desde finales del siglo XVI hasta la Desamortización del XIX en las iglesias alzireñas.

De 1985 también hay que citar el artículo de Joan Carrasco "Capítulos por los que se rige el cargo de maestro de capilla de la iglesia de Santa María de Elche. Año 1700”, incluido en la revista Pobladores de Elche $e^{59}$. Se trataba de un breve trabajo con la transcripción del citado documento y algunos comentarios sobre el mismo. Sin embargo, fue mucho más interesante el amplio artículo de este mismo autor recogido un año más tarde, 1986, en la revista Cabanilles, con el título: "La música en la iglesia de Santa María de Elche" ${ }^{60}$. Este trabajo comenzaba con una aproximación histórico-constructiva al templo ilicitano y una introducción al «Misterio de Elche». Después de ello, se introducía un amplio epígrafe con la evolución de la capilla musical del templo -siglos XVI-XIX-, tomando siempre como hilo conductor la celebración del «Misterio». A continuación, se recogía un apartado con los datos obtenidos por el autor de cada uno de los maestros de capilla que intervinieron en el templo ilicitano, siguiendo con otro epígrafe similar referido al resto de músicos. Tras esto, se estudiaba los órganos construidos en el templo y la figura de sus organeros y organistas, ofreciendo después noticias sobre el resto de instrumentos que también se utilizaron, todo ello centrado de nuevo en el «Misterio». Finalmente, el estudio recogía un espacio sobre los libros y papeles de música utilizados en la iglesia a través del tiempo.

56 ZUDAIRE HUARTE, 2 (San Sebastián, 1985): 79-101.

57 BAGÜÉS ERRIONDO, 2 (San Sebastián, 1985): 157-184.

58 ALONSO CLIMENT, 14-16 (Valencia, 1985): 9-180.

59 CASTAÑ̃ GARCÍA, 7 (Elche, 1985): sin paginar.

60 CASTAÑO GARCÍA, 18-20 (Valencia, 1986): 13-164. 
De la revista Cabanilles de 1986 también hay que mencionar los artículos “Orgue de Callosa d'en Sarrià [1845]”, "Un orgue per a la Capella de la Mare de Déu de Gràcia a l'església de Sant Agustí de Valencia (1503)" y "Un orgue per a la parroquia de Sant Tomàs de Valencia (1489)", de Josep Lluis Berenguer y Joan Baptista Díaz el primero, y de Josep Nicolau los dos siguientes, donde se estudiaba la construcción de dichos instrumentos ${ }^{61}$.

Otro artículo de 1986 sobre órganos fue el de Juan Cruz Labeaga aparecido en la Revista de Musicología con el título: "Órganos y organistas de Sangüesa (Navarra)" ${ }^{62}$. En él, tras una breve introducción sobre la importancia de Sangüesa como centro organero del siglo XVI, Labeaga hacía un estudio musical de las tres parroquias de la ciudad -el Salvador, Santa María y Santiago- entre los siglos XVI y XX. Así, exponía los datos hallados sobre órganos construidos en cada una de ellas, costeados con los fondos económicos eclesiásticos, el ayuntamiento de la ciudad, los fieles e incluso mecenas. Tras ello, también se dedicaban epígrafes a los organistas, en cuanto a formalización de contratos, obligaciones, emolumentos, etc. Para terminar, el autor recogía brevemente un dato interesante, como es el hecho de que Sangüesa contó con capilla de música al menos en el siglo XIX.

En 1987 se publicaron dos nuevos trabajos sobre la ya citada iglesia de Santa María de Elche, ambos en la revista Monsalvat. El primero de ellos se titulaba "Tradición y modernidad en el Misterio de Elche”, de María del Carmen Gómez, donde se hacía un interesante estudio de los posibles antecedentes musicales de este drama litúrgico hallados en el monasterio de Santa María del Estany y en la ciudad de Tarragona ${ }^{63}$. Finalmente, la autora describía el contenido del manuscrito ilicitano de 1709 donde está recogido el «Misterio» representado en la actualidad, aunque haciendo referencia a la pérdida de otros manuscritos anteriores. Por su parte, el segundo de los trabajos incluido en la revista Monsalvat de 1987 fue el de Jesús Francesc Massip titulado: "El Misterio de Elche. Sobre las obligaciones del maestro de capilla" ${ }^{64}$. Se trataba de un complemento perfecto al artículo que publicó Joan Castaño en la revista Pobladores de Elche de 1985, ya que analizaba el documento de 1700 donde aparecen las obligaciones del maestro de capilla de la iglesia de Santa María de Elche y también recogía datos sobre las funciones del mismo según otros documentos del siglo XVI y XVIII. Sin embargo, el artículo de Massip no aportaba datos nuevos respecto al trabajo de Joan Castaño aparecido en la revista Cabanilles de 1986 sobre la iglesia ilicitana.

En 1987 también se publicó una breve monografía titulada Apunts sobre el fet musical a Felanitx, de Pere Estelrich, Biel Massot y Joan Parets ${ }^{65}$. Respecto al tema parroquial, lo interesante es que en el estudio se recogía un breve epígrafe con algunos datos sobre los órganos, organeros y organistas de la iglesia felanigense de San Miguel -siglos XVI-XX-.

61 BERENGUER y DÍAZ, 17 (Valencia, 1986): 4-10, 23-24. NICOLAU BAUZÁ, 17 (Valencia, 1986a): $25-26 ; 17$ (Valencia, 1986b): 27-29.

62 LABEAGA MENDIOLA, 9/1 (Madrid, 1986): 57-96.

63 GÓMEZ MUNTANER, 151 (Barcelona, 1987): 9-13.

64 MASSIP BONET, 151 (Barcelona, 1987): 14-18.

65 ESTELRICH I MASSUTTÍ, MASSOT I MUNTANER y PARETS Y SERRA, 1987. 
Otro trabajo de 1987 fue el artículo de Claudio Zudaire sobre "La vida musical en la parroquia navarra de Falces (siglos XVII al XIX)", que apareció en la Revista de Musicología ${ }^{66}$. Este estudio presentaba las noticias sobre los organistas de dicha iglesia, los maestros de capilla y el resto de músicos que actuaron en el templo durante el siglo XVII. Tras ello, se compendiaba la historia de la música de la parroquia de Falces durante el siglo XVIII, desde los órganos que se construyeron en el templo hasta la decadencia paulatina de la actividad musical, que llevó a que los músicos asumiesen más de una plaza. Finalmente, el estudio aportaba datos musicales de la iglesia falcesina referidos al siglo XIX y primeras décadas del $\mathrm{XX}$, confirmando la decadencia progresiva de la actividad musical y la desaparición de la capilla en la primera de estas dos centurias.

La revista Cabanilles de 1987 también incluyó algunos artículos de parroquias: el primero de ellos fue el de Francisco Candel sobre los “Órganos de don Matías Salanova en Murcia, 1763-1777”, donde estudiaba los instrumentos construidos por el citado organero tanto en conventos como en parroquias, caso este último de San Bartolomé de Beniel o de Santa Catalina de Murcia ${ }^{67}$; el segundo artículo, de Joan Baptista Díaz y titulado "El órgano de Montesa", comentaba la existencia de restos de un instrumento del siglo XVIII en la parroquia de la Asunción de la villa ${ }^{68}$; el tercer trabajo, "Nuevos documentos sobre órganos del maestrazgo", de Vicente Ros, se centraba en instrumentos de iglesias de Catí y La Mata ${ }^{69}$; por último, el cuarto artículo, de Josep Lluis Berenguer y Joan Baptista Díaz, versaba sobre el "Órgano de [la parroquia de] Santa Bárbara (Rocafort)", de finales del siglo $\mathrm{XX}^{70}$.

Otro artículo que se publicó en 1987 fue el de Pedro Jiménez titulado "La música en la Santa Capilla de San Andrés. Notas históricas", concretamente en el Boletín del Instituto de Estudios Giennenses ${ }^{71}$. Esta Santa Capilla era una fundación privada establecida en la parroquia de San Andrés de Jaén, que tenía fines benéficos, docentes y piadosos. Entre los últimos se encontraba la solemnidad del culto divino, creándose una capilla musical en el primer tercio del siglo XVI cuya organización analizaba Pedro Jiménez en su trabajo de 1987. Tras ello, el investigador hacía un estudio de la capilla de música siglo a siglo, con nombres de personajes, aspectos económicos y de funcionamiento; así, exponía cómo este grupo actuó en la iglesia de San Andrés desde el siglo XVI hasta principios del XIX, cuando por problemas de financiación se suprimieron las plazas de maestro de capilla, cantores y ministriles, manteniendo sólo la de órgano y las dedicadas al canto llano.

En 1988 la revista Cabanilles continuó publicando varios artículos en torno a la música parroquial. El primero, de Javier Sánchez, se dedicaba al estudio de "Los órganos de la iglesia de la Merced de Orihuela [entre los] siglos XVII-XX"ᄁ2; el segundo, de Josep Lluís Fos y titulado "Nuevas aportaciones a la música suecana del XVII", daba el nombre y el cargo de diversos músicos que ejercieron en la villa

66 ZUDAIRE HUARTE, 10/3 (Madrid, 1987): 843-878.

67 CANDEL CRESPO, 21 (Valencia, 1987): 5-37.

68 DÍAZ, 22 (Valencia, 1987): 3-6.

69 ROS PÉREZ, 22 (Valencia, 1987): 23-28.

70 BERENGUER y DÍAZ, 24 (Valencia, 1987): 5-8.

71 JIMÉNEZ CAVALLÉ, 129 (Jaén, 1987): 9-31.

72 SÁNCHEZ PORTAS, 25 (Valencia, 1988): 5-21. 
valenciana de Sueca, demostrando la existencia de una capilla musical al menos desde $1610^{73}$; el tercer artículo, de Miguel Alonso, estudiaba la historia de "El órgano de la parroquia de San Valero de Valencia", desde el siglo XVI hasta mediados del $\mathrm{XX}^{74}$; para terminar, el cuarto de los artículos fue el de Antonio Andrés y José Ramón Sanchís sobre "El órgano de Alaquàs", centrado en el instrumento que, con el patrocinio municipal, construyó en la parroquia alacuasense de la Asunción el organero Nicolás Salanova en el siglo XVIII ${ }^{75}$.

Otro artículo de 1988 que trató el tema parroquial fue el de Claudio Zudaire publicado en la revista Cuadernos de Sección-Música con el título: "Simón de Artozqui: primer organista de Hernani”76. En este trabajo se ofrecían los datos sobre la construcción de un órgano en la parroquia hernaniense de San Juan a mediados del siglo XVII, estudiando también al primer músico contratado para tañerlo y cómo éste fue destituido un tiempo más tarde por el interés del concejo de la localidad -patrono de la iglesia- en contratar a otro personaje; eso sí, con la oposición del cabildo eclesiástico. Además, de 1988 también fue el artículo de Francesc Bonastre publicado en Anuario Musical donde transcribía y analizaba un documento sobre "L'obra de fra Bartolomeu Triay a l'orgue de Torroella de Montgrí [de] 1682" "77; y la monografía de Louis Jambou sobre la Evolución del órgano español. Siglos XVI-XVIII, con muchos datos sobre instrumentos construidos en parroquias de toda España ${ }^{78}$.

Ya en 1989 se publicó un reducido libro titulado El órgano de la iglesia de San José en el complejo conventual de las Carmelitas de Caravaca, trabajo de José Antonio Melgares ${ }^{79}$. Como resulta evidente, el núcleo del estudio se dedicaba al órgano del centro regular, pero lo interesante es que también recogía datos sobre los órganos que construyó José Folch a finales del siglo XVIII en la iglesia del Santuario de la Vera Cruz y en la del Salvador de Caravaca, aludiendo incluso a la existencia de una capilla de música en este último templo gracias al patrocinio del concejo de la villa.

\section{LA DÉCADA DE 1990}

Un año más tarde del trabajo sobre Caravaca, en 1990, José Luis Ruiz publicó un breve capítulo de libro con el título: "Un aspecto ignorado para la historia: la música en la vida local. La capilla de música de la iglesia parroquial de Nuestra Señora de la Asunción y Ángeles de Cabra (Córdoba)" "80. En él, se informaba de las escasas fuentes primarias egabrenses y se aclaraba de forma genérica el concepto de capilla musical. Ya en el epígrafe dedicado a la capilla del templo de Nuestra Señora de la Asunción y Án-

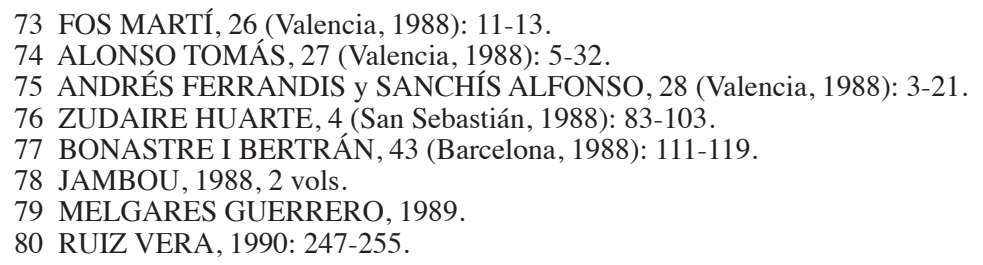


geles de Cabra, quedaban recogidas noticias sobre las plazas musicales y los personajes que las ocuparon, aunque la parquedad de las fuentes sólo permitía ofrecer datos exiguos y cronológicamente dispersos. En cualquier caso, se demostraba cómo la citada iglesia contó con sochantre y organista al menos desde la segunda mitad del siglo XVI, mientras que en el XVII y XVIII ya se documenta una capilla musical con maestro y varios intérpretes de voz e instrumento.

De 1990 también fueron dos artículos de la revista Cabanilles dedicados a la música en parroquias. El primero, de Josep Antoni Lluesma, estudiaba "Los órganos de Santa María de Sagunto y el mundo musical de su entorno" ". Así, trataba del coro de los oficios y la intervención del sochantre y los beneficiados de la iglesia como intérpretes de canto llano en el mismo, aunque también daba la noticia de cómo desde el siglo XVII había igualmente una capilla de música dedicada al canto de órgano. Después, se presentaba un epígrafe con algunos datos sobre organistas, para finalizar estudiando los distintos órganos construidos en la iglesia -desde finales del siglo XV hasta el XVIII- y a los responsables de los mismos.

Por su parte, el segundo de los artículos en torno a la música parroquial de la revista Cabanilles de 1990 fue el de Joan Ramón Giménez, sobre los "Orgues i organistes a Albalat de la Ribera"\$2. En él se hacía un estudio histórico de los diferentes órganos del templo albalatero de Sant Pere-desde el siglo XVI hasta el XX-, pasando después a tratar sobre los organistas de los mismos y de cómo estos personajes solían ejercer de forma paralela el magisterio de la capilla musical existente en la iglesia al menos en los siglos XVII y XVIII. Para concluir, el artículo ofrecía datos sobre el resto de miembros de dicha capilla, que muchas veces eran foráneos contratados eventualmente para las fiestas más importantes.

El siguiente trabajo publicado sobre la música en una parroquia fue el artículo de Claudio Zudaire de 1991 titulado "La organistía de Motrico (s. XVII-XVIII)", incluido en la revista Cuadernos de Sección-Música ${ }^{83}$. En él se informaba de que la iglesia motriquesa de Santa María ya contó con órgano en la primera mitad del siglo XVI, cuyos tañedores fueron medio beneficiados, es decir, tenían una renta aneja a su ministerio eclesiástico. Sin embargo, la coincidencia de las tareas musicales y las propias del medio beneficio hacían que los organistas no siempre pudieran compatibilizarlas. Por ello, el concejo de Motrico, como patrono de la iglesia, y el cabildo beneficial de ésta, firmaron una Concordia en 1765 para que la organistía recayese en músicos legos, fijando también las obligaciones de la plaza.

Poco después del trabajo sobre Motrico, en 1992, apareció el libro de Jesús Villalmanzo titulado La música en la parroquia de los Santos Juanes de Valencia durante el siglo XVIII, la primera monografía íntegra sobre una iglesia con rango parroquial ${ }^{84}$. Esta investigación recogía un interesante epígrafe que explicaba cómo no sólo la catedral de Valencia contó con capilla de música, sino que varias parroquias de la ciudad también dispusieron de la suya. No obstante, Villalmanzo apuntaba que estas últimas no dependían directamente de las iglesias cuya advocación tomaban por nombre, sino que eran grupos musicales externos que actuaban de forma fija en las fiestas de mayor categoría litúrgica de un determinado templo.

81 LLUESMA I ESPANYA, 33 (Valencia, 1990): 3-48.

82 GIMÉNEZ ÚBEDA, 34-36 (Valencia, 1990): 7-111.

83 ZUDAIRE HUARTE, 5 (San Sebastián, 1991): 9-22.

84 VILLALMANZO CAMENO, 1992. 
Esta vinculación eclesiástica proporcionaba a las capillas contratos para actuar en otros centros religiosos, mientras que a sus iglesias de referencia les aseguraba solemnizar los principales cultos. En concreto, el estudio se dedicaba primero a los órganos con los que contó el templo parroquial de los Santos Juanes, a los organeros que intervinieron en los mismos y a los intérpretes de dichos instrumentos, pasando después a ofrecer noticias de los maestros y del resto de músicos que conformaban la capilla interviniente en los cultos.

Sólo un año más tarde de dicha publicación, es decir, en 1993, apareció en la revista Anuario Musical un artículo de Josep Pavia titulado: "La música a la parròquia de Sant Just i Sant Pastor de Barcelona, durant el segle XVII" ${ }^{85}$. Éste comenzaba con una introducción histórica y organizativa sobre la citada iglesia catalana, pasando después a estudiar la creación de la plaza del magisterio de capilla a finales del siglo XVI y los personajes que la ostentaron. Seguidamente se recogían todas las referencias de los clérigos examinados de interpretación vocal para acceder a un beneficio en la iglesia, enumerando más tarde los días en los que se cantaba en el templo según el calendario litúrgico. Para terminar, se presentaban noticias sobre los niños cantores, sochantres, organistas, órganos y organeros del centro barcelonés.

En 1994, José Ignacio Palacios publicó un libro de Órganos y organeros en la provincia de Soria, donde estudiaba los instrumentos históricos de diferentes centros religiosos y, entre ellos, los de casi setenta parroquias ${ }^{86}$. Algo similar hacían Françoise Clastrier y Óscar Candendo este mismo año en su artículo sobre los "Órganos franceses en el País Vasco y Navarra (1855-1925)", recogido en la revista Cuadernos de Sección-Música, sólo que referido a las circunscripciones vasca y navarra en el periodo cronológico citado ${ }^{87}$.

Ya en 1995 se publicó un nuevo artículo que contenía referencias a la música parroquial; se trataba del de Pedro María Flamarique sobre los "Músicos y música en Tafalla”, recogido en la revista Cuadernos de Cultura Tafallesa ${ }^{88}$. En este trabajo se presentaba la biografía de diversos músicos, sobre todo del siglo XX y ligados a la interpretación profana, aunque también la de algunos como Felipe Gorriti, maestro de capilla y organista de la iglesia de Santa María de Tafalla en la segunda mitad del XIX. Además, el artículo recogía un interesante apéndice con listados cronológicos de los sucesivos maestros de capilla, organistas y ministriles que actuaron en el citado templo, pero también de los organistas que ejercieron en la iglesia tafallesa de San Pedro.

De 1995 fue igualmente el libro de Juan Ruiz sobre la Organería en la Diócesis de Granada (1492$1625)^{89}$. En él se estudiaba la difusión del órgano en la demarcación eclesiástica granadina, los tipos de instrumentos, sus aspectos técnicos y las condiciones socio-económicas y artísticas para la construcción de los mismos. En cuanto al tema parroquial, lo más interesante fue que el trabajo incluía un apéndice con numerosos datos sobre los órganos de una veintena de templos de la provincia de Granada y las sucesivas

85 PAVIA I SIMÓ, 48 (Barcelona, 1993): 103-142.

86 PALACIOS SANZ, 1994.

87 CLASTRIER y CANDENDO ZABALA, 7 (San Sebastián, 1994): 145-212.

88 FLAMARIQUE, 8 (Tafalla, 1995): 1-139.

89 RUIZ JIMÉNEZ, 1995. 
intervenciones en los mismos durante el periodo estudiado, además de ofrecer unos apuntes biográficos sobre los organeros encargados de su construcción o arreglo.

En 1995 también vio la luz un nuevo libro sobre órganos, el de Andrés Cea e Isabel Chía titulado Órganos en la provincia de Cádiz. Inventario y catálogo, donde se catalogaban y describían los instrumentos de más de cincuenta parroquias ${ }^{90}$. En realidad, se trataba del primer libro de una serie que se dedicó a catalogar los órganos de las distintas provincias andaluzas. Así, por ejemplo, en 1996, Andrés Cea e Isabel Chía se encargaron nuevamente de estudiar y inventariar los instrumentos de más de una decena de parroquias onubenses; en 1997, Adalberto Martínez hizo lo propio con casi veinte iglesias malagueñas; e igualmente, en 1998, José Enrique Ayarra catalogó más de ochenta órganos de parroquias sevillanas ${ }^{91}$.

En este último año, 1998, la revista Nassarre también recogió dos artículos sobre la música en parroquias. El primero, de Francisco Candel, transcribía el "Contrato para la construcción del órgano de la iglesia parroquial de San Bartolomé, en Murcia, por Miguel Alcarria. 1817”, dedicando también un amplio epígrafe a estudiar la vida y la obra del organero ${ }^{92}$. El segundo de los artículos aparecidos en Nassarre sobre el tema parroquial fue el de María Gembero titulado: "El patronazgo ciudadano en la gestión de la música eclesiástica: la parroquia de San Nicolás de Pamplona (1700-1800)"933. Este trabajo estudiaba cómo algunas iglesias parroquiales, caso de la pamplonesa de San Nicolás, funcionaron bajo el control de los feligreses a través de diversas juntas que, lógicamente, también controlaron los temas musicales. En concreto, el templo objeto de estudio no contó con capilla musical, sino sólo con un organista y con los clérigos de la iglesia que cantaban durante los cultos. Respecto a la música, el artículo presentaba un espacio sobre los órganos y los organistas del templo en el siglo XVIII, tratando del acceso de estos últimos a sus plazas, sus obligaciones y derechos. Con ello se pasaba a estudiar a los coristas -que eran todos los clérigos de la iglesia-, analizando su número, procedencia, sistema de acceso, normativa y nivel socioeconómico. Tras este bloque, se recogía un epígrafe sobre los organeros y los encargados de los fuelles de los órganos, pasando después al estudio del repertorio interpretado en la iglesia.

De 1998 también fue el artículo de María Gloria Cano sobre "La capilla de música de la iglesia prioral de El Puerto de Santa María durante el siglo XVIII", publicado en la Revista de Historia de El Puerto $^{94}$. En este trabajo se recogía cómo la iglesia portuense sólo contó con un organista en el siglo XVII, mientras que a principios de la siguiente centuria ya dispuso de una capilla de música gracias a la colaboración económica de la fábrica eclesiástica, del concejo de la ciudad y de algunas cofradías locales. Básicamente, el artículo estudiaba el reglamento de 1724 por el que se regía dicha capilla, pero también ofrecía datos sobre los integrantes de la misma durante el siglo XVIII o el sistema de acceso a las plazas.

Por último, de 1998, también hay que hacer mención a las cuatro comunicaciones sobre música parroquial recogidas en las Actas del IV Congreso de Historia de Navarra. La primera de ellas, titu-

90 CEA GALÁN y CHÍA TRIGOS, 1995.

91 CEA GALÁN y CHÍA TRIGOS, 1996. MARTÍNEZ SOLAESA, 1997. AYARRA JARNE, 1998.

92 CANDEL CRESPO, 14/1 (Zaragoza, 1998): 251-267.

93 GEMBERO USTÁRROZ, 14/1 (Zaragoza, 1998): 269-362.

94 CANO RÉVORA, 20 (El Puerto de Santa María, 1998): 45-64. 
lada "Cantorales de la merindad de Estella" y con autoría de Ana Isabel Esparza, informaba de los 128 libros de canto llano custodiados en diferentes parroquias de la citada comarca navarra, haciendo una descripción de los mismos, analizando su contenido y ofreciendo datos sobre los copistas ${ }^{95}$. Un planteamiento similar de estudio hacían Beatriz Gurbindo y María del Burgo Moreno en sus respectivas comunicaciones tituladas: "Los cantorales de la iglesia parroquial de San Andrés de Villava y otras noticias musicales"; y "Cantorales en la merindad de Tudela" ${ }^{\circ 6}$. Así, en el primer trabajo se estudiaban los siete libros de canto llano que se conservan en Villava, ofreciendo también algunos datos sobre los órganos y organistas de la iglesia de San Andrés entre los siglos XVII y XIX; por su parte, en el segundo se informaba de los 137 cantorales hallados en las parroquias de la Merindad navarra de Tudela, describiéndolos, analizando su contenido y tratando sobre los copistas de los mismos. La última de las comunicaciones recogidas en el libro de Actas la dedicó Berta Moreno a un músico ya citado, "Felipe Gorriti: maestro de capilla de Tafalla (1859-1867)"97. Así, trataba de la oposición que hizo el músico en 1859 al magisterio de capilla de la iglesia tafallesa, de sus condiciones laborales o de su obra compositiva.

Un año más tarde de estas cuatro comunicaciones, en 1999, la revista Anuario Musical recogió el artículo "Organistes y mestres de capella de la Diòcesi de Girona”, de Josep Maria Marquès, complemento perfecto a los trabajos publicados por Francesc Civil en la década de 1970 sobre la música gerundense ${ }^{98}$. Así, el estudio de Marquès analizaba cómo en la mayoría de parroquias los cargos de organista y maestro de capilla fueron beneficios, aunque también podían ser capellanías, fundaciones privadas o plazas cubiertas mediante el establecimiento de contratos entre músicos e iglesias -o los patronos de éstas, generalmente concejos locales-.

Para finalizar con los trabajos del siglo XX y conectar con los del XXI, hay que hacer mención al Diccionario de la música española e hispanoamericana, dirigido por Emilio Casares y publicado entre 1999 y 2002 , puesto que presentaba gran información sobre música religiosa ${ }^{99}$. Sin embargo, resulta curioso que entre las voces del Diccionario se encontrasen las de "Catedrales" y "Colegiata", pero no la de "Parroquia". A pesar de ello, la obra recogía entradas de determinadas poblaciones y provincias con datos sobre órganos, organeros, intérpretes y actividad musical en parroquiales, como las correspondientes a Albacete, Alicante, Andújar, Bilbao, Cabra, Cáceres, Corella, Guipúzcoa, Mérida, Olot, Tafalla, Tenerife, Trujillo, Tudela, Úbeda o Valladolid. Además, en el Diccionario también aparecían voces de músicos que en algún momento desarrollaron sus carreras profesionales en parroquias, caso de Gregorio Brufal, Cristóbal de Medrano o el ya citado Felipe Gorriti.

95 ESPARZA AZCONA, 1998, vol. 2: 399-406.

96 GURBINDO GIL, 1998, vol. 2: 407-411. MORENO IZAL, 1998, vol. 2: 423-430.

97 MORENO MORENO, 1998, vol. 2: 431-441.

98 MARQUĖS I PLANAGUMÂ, 54 (Barcelona, 1999): 89-130.

99 CASARES RODICIO, 1999-2002, 10 vols. 


\section{EL SIGLO XXI}

Este siglo se inauguró con la publicación en 2000 del capítulo de libro titulado "La capilla musical de Santiago: una institución peculiar”, incluido por Carmen Rodríguez en el volumen: La catedral de Santiago. Bilbao ${ }^{100}$. Sobre el título del trabajo debe aclararse que la iglesia bilbaína de Santiago tiene actualmente el rango catedralicio, pero que dicha categoría no se le otorgó hasta 1949. En cuanto al capítulo de Carmen Rodríguez, éste comenzaba exponiendo que el templo de Santiago tenía por patrono al ayuntamiento de la villa, es decir, la institución civil era responsable de sufragar los gastos del centro religioso y, en consecuencia, también de nombrar a sus músicos. Después, la autora establecía la diferencia entre los intérpretes eclesiásticos y los que no lo eran, estando los primeros dedicados principalmente al canto llano y los segundos a la polifonía. Tras esto, se estudiaba la jerarquía musical de la iglesia y el sistema para reclutar a los intérpretes, pasando después a situar los comienzos de la capilla de Santiago en las últimas décadas del siglo XVI y a ofrecer datos sobre algunos de sus maestros y organistas. A continuación, se señalaba el funcionamiento de la capilla bilbaína y las obligaciones de sus miembros, terminando con el estudio económico del grupo y los inventarios de papeles y libros de música realizados -siglos XVI-XIX-.

En 2002, Esteban Elizondo publicó un libro con el título: La organería romántica en el País Vasco y Navarra (1856-1940) ${ }^{101}$. Esta obra era un complemento perfecto al artículo que en 1994 escribieron Françoise Clastrier y Óscar Candendo sobre los órganos de constructores franceses en la misma época y zona geográfica. Así, Esteban Elizondo estudiaba la evolución del órgano romántico en territorio vasconavarro y analizaba los órganos de constructores franceses, españoles y alemanes en la zona, la mayor parte de ellos parroquiales.

En este mismo año, 2002, Francesc Xavier Torres publicó un libro titulado Música i músics a l'Eivissa dels segles XVI, XVII i XVIII, un trabajo que se centraba principalmente en el estudio musical de la parroquia ibicenca de Santa María -que ostentó dicho rango hasta que en 1784 fue erigida catedral- ${ }^{102}$. En primer término, la obra recogía una pequeña introducción al objeto de estudio, a la que seguía un espacio con noticias sobre la música ceremonial interpretada en las calles ibicencas desde el siglo XIV hasta el XVIII. Tras esto, el trabajo presentaba el capítulo más extenso e importante del mismo, dedicado a la actividad musical en la iglesia de Santa María. En él se estudiaba la creación de las plazas de organista, maestro de capilla y sochantre, se ofrecían datos sobre los personajes que las ostentaron entre los siglos XV y XVIII y, para terminar, se hacía referencia a la economía de estos músicos. Ya en otro capítulo, quedaban recogidas noticias sobre los instrumentos utilizados en la localidad de Ibiza desde el siglo XIV hasta el XVIII, con especial atención a los sucesivos órganos y campanas de los que dispuso la iglesia de Santa María. Tras ello se introducían otros capítulos sobre los libros musicales conservados en el citado templo, los encargados de accionar los fuelles de los órganos o la relación entre la música y el calendario litúrgico.

100 RODRÍGUEZ SUSO, 2000: 167-195.

101 ELIZONDO IRIARTE, 2002.

102 TORRES I PETERS, 2002. 
Además de este libro, en 2002 también se publicó otro que estudiaba musicalmente una parroquia, con el título: La música y los músicos en la iglesia riojana de Briones: formación de un archivo musical parroquial $^{103}$. Esta monografía, realizada por María Pilar Camacho, planteaba en el primer capítulo el marco geográfico, histórico e institucional del trabajo, mientras que en el segundo analizaba la vida musical desarrollada en la iglesia brionera de Santa María de la Asunción, sobre todo la referida al siglo XVIII. Así, trataba de los beneficiados del templo y de su participación como cantores en los oficios divinos, dirigidos por el sochantre. Además, estudiaba brevemente cada una de las plazas que conformaban la capilla de música con la que contó el templo -maestro, organista, cantores y ministriles-, pasando después a referirse al ceremonial de la iglesia y a la inclusión de música en el mismo. Tras ello comenzaba la parte más prolija del volumen, dedicada a la catalogación del repertorio conservado.

De 2002 también fue un artículo de Joan Serra y Josep Maria Martí que presentaba en Anuario Musical el listado de los "Orgues i harmònius destruïts durant la Guerra Civil (1936-1939) a les parròquies de la Diòcesi de Barcelona"104, mientras que en 2004, dos años después, Olga Sánchez publicó una monografía dedicada a La actividad artístico-musical de Albacete en la segunda mitad del siglo XIX ${ }^{105}$. En ella se recogía un capítulo sobre música religiosa, donde la autora informaba de que la iglesia parroquial de San Juan Evangelista de Albacete contó durante el periodo estudiado con un nutrido grupo instrumental, que acompañaba asiduamente los cantos de los feligreses y sacerdotes durante las funciones litúrgicas. Sin embargo, debe aclararse que no se trataba de un conjunto dependiente de la iglesia, sino de una agrupación musical adscrita a la parroquia.

Ya en 2005, Antonio Ramírez y Manuel Antonio Ramos publicaron el volumen titulado: Catálogo del archivo musical de la parroquia de San Juan Bautista de Marchena (Sevilla) ${ }^{106}$. Esta obra comenzaba con una breve introducción, señalando la importancia del archivo musical del templo parroquial marchenero, el orden alfabético de autores utilizado para presentar el catálogo y el empleo de los criterios RISM en las fichas de las obras. Justo después se recogía el catálogo de las fuentes musicales conservadas en el archivo de la parroquia de San Juan Bautista, lo que constituía el núcleo central del libro. Finalmente, el trabajo presentaba un breve espacio sobre los maestros de capilla que ejercieron en Marchena.

Además, en 2005 Rosario Álvarez y Lothar Siemens incluyeron un capítulo dedicado a la música de iglesias parroquiales en su libro La música en la sociedad canaria a través de la historia ${ }^{107}$. En dicho capítulo se analizaba la inclusión musical en los cultos, sobre todo según las disposiciones episcopales del siglo XVI, destacando la interpretación del canto llano en los oficios y misas de forma directamente proporcional a la plantilla eclesiástica de cada templo. Así, había algunas parroquias que incluso contaban con sochantre, cargo que frecuentemente asumía el sacristán del centro en cuestión. Sin embargo, los autores también apuntan otro hecho relevante, como es que ciertas parroquiales dispusieron de algunos

103 CAMACHO SÁNCHEZ, 2002.

104 SERRA SANMIGUEL y MARTÍ I BONET, 57 (Barcelona, 2002): 251-275.

105 SÁNCHEZ HUEDO, 2004.

106 RAMÍREZ PALACIOS y RAMOS SUÁREZ, 2005.

107 ÁLVAREZ MARTÍNEZ y SIEMENS HERNÁNDEZ, 2005: 271-292. 
músicos para cantar polifonía en las fiestas solemnes, señalando el nombre de unos pocos de ellos. Por último, en este capítulo también se exponen diversos datos sobre órganos parroquiales de las Islas Canarias, sus constructores e intérpretes.

Un año más tarde de este capítulo, en 2006, Juan Cruz Labeaga publicó en la revista Príncipe de Viana un nuevo artículo titulado "La capilla de música de Santa María de Viana, Navarra (siglos XVI-XIX)" 108 , que venía a completar el que con el título "La música en la parroquia de Santa María de Viana (Navarra), siglos XVI y XVII” había incluido en este mismo medio de divulgación científica en 1980. Básicamente, en el artículo de 2006 el autor retomaba los datos recogidos en el de 1980, aunque variaba la estructura para ofrecerlos. La novedad del trabajo más reciente fue la inclusión de epígrafes dedicados a los siglos XVIII y XIX. Así, en cuanto al siglo XVIII, el artículo presentaba las noticias musicales sobre la iglesia de Santa María de Viana contenidas en las disposiciones episcopales. Tras ello, se introducía un epígrafe sobre la recuperación de la capilla musical en la segunda mitad del siglo XVIII, suprimida a finales del siglo anterior por el endeudamiento económico del templo. Seguidamente, el artículo estudiaba a los maestros de capilla, músicos de instrumento -incluyendo a los organistas-, cantores -con los sochantres e intérpretes del canto de órgano- y el repertorio polifónico que contenían los inventarios realizados en el siglo XVIII. Para terminar, el trabajo de Labeaga incorporaba un epígrafe sobre la nueva supresión de la capilla de música a principios del siglo XIX, quedando como único recurso el organista.

En el mismo número de Príncipe de Viana de 2006 que recogía este artículo también había otro titulado "La vida musical de Tafalla (Navarra) en la época de Felipe Gorriti (1859-1867)", de Berta Moreno, complemento perfecto al que esta misma autora publicó en 1998 sobre el músico ${ }^{109}$. En concreto, el trabajo de 2006 señalaba cómo la localidad tafallesa dispuso de dos parroquias en el siglo XIX, las de Santa María y San Pedro, ambas pertenecientes a un mismo patronato formado por representantes del ayuntamiento y del cabildo eclesiástico -integrado por once beneficiados que ejercían sus funciones en ambas iglesias rotatoriamente-. Por tanto, dichas parroquias contaron con grupos de clérigos que cantaban en los oficios divinos y misas, a los que se añadía el respectivo organista de cada templo. Además, la iglesia de Santa María dispuso de capilla de música, recogiéndose en el artículo datos de su composición, emolumentos de los miembros o actividad interpretativa.

Otro estudio que contiene información sobre música parroquial es el de Lluís Brugués titulado La música a Girona, de $2008^{110}$. En concreto, este volumen recoge un capítulo dedicado a la música religiosa en la ciudad catalana, informando de que parroquias como el Carme y Santa Susanna del Mercadal dispusieron de escolanías durante el siglo XX, es decir, coros de niños que cantaban durante las celebraciones litúrgicas. Además, también aporta el nombre de algunos organistas que ejercieron en las citadas parroquias -siglos XIX-XX-.

108 LABEAGA MENDIOLA, 238 (Pamplona, 2006): 389-424.

109 MORENO MORENO, 238, (Pamplona, 2006): 561-576.

110 BRUGUÉS I AGUSTÍ, 2008. 
Entre los trabajos más recientes que ofrecen datos sobre iglesias no catedralicias ni colegiales también se encuentra el de 2009 de Salvador Daza titulado: Música y sociedad en Sanlúcar de Barrameda (1600-1975) ${ }^{111}$. Exactamente, el volumen dedica una primera parte al estudio musical de los templos sanluqueños de Nuestra Señora de la O y Nuestra Señora de la Caridad, ambos patrocinados por los señores de la ciudad, los duques de Medina Sidonia. Así, se sabe que dicha casa nobiliaria ya mantenía en la primera de estas dos iglesias una capilla de música en 1535, formada por diez capellanes, cuatro mozos y veinticuatro músicos, tanto vocales como instrumentales. Sin embargo, este grupo se vio reducido a sólo un sochantre y un organista cuando el VIII duque de Medina Sidonia, Juan Manuel Pérez de Guzmán, fundó la iglesia de la Caridad en 1610 y dedicó a ella sus mayores esfuerzos económicos, dotándola de una capilla de música que se mantuvo hasta finales del siglo XIX y cuyo devenir histórico es analizado con detalle en el libro de Daza.

Otro trabajo publicado en 2009 es el de Francesc Bonastre y Josep Maria Gregori sobre los Fons de l'església parroquial de Sant Pere i Sant Pau de Canet de Mar ${ }^{112}$, un templo que dispuso de comunidad de presbíteros y que recibió el patrocinio del concejo de la villa -por ello, aspectos como la contratación de músicos debían consensuarse entre los representantes de ambas instituciones-. En concreto, el libro consta de dos volúmenes: el primero analiza la historia, importancia, estética y presentación de dichos fondos, a la vez que estudia la capilla de música de la iglesia de Sant Pere i Sant Pau -centrándose en el siglo XVIII- y ofrece los datos biográficos de los compositores de Canet de Mar cuyas obras son catalogadas seguidamente. Por su parte, en el segundo volumen se procede al catálogo de las composiciones anónimas conservadas en el archivo parroquial canetense, que junto a las de autores conocidos suman más de dos mil -siglos XVII-XX-. Además, Francesc Bonastre también coordinó en 2009, junto a Francesc Cortès, la edición de la Història crítica de la música catalana, un trabajo con capítulos sobre aspectos relevantes como la canción popular o la musicología en Cataluña, a los que se suman otros dedicados al análisis de cada uno de los periodos históricos - desde la Edad Media hasta el siglo XXI- ${ }^{113}$. Es en estos últimos donde aparecen diversas referencias puntuales a la actividad musical desarrollada en algunas parroquias, destacando el epígrafe que sobre los centros religiosos barceloneses de este rango inserta Josep Maria Gregori en su capítulo dedicado al Renacimiento musical en Cataluña ${ }^{114}$.

Uno de los últimos estudios realizado en España sobre una parroquia es la tesis doctoral que presentamos en 2009, con el título: La música en la iglesia de Santa María de Huéscar hasta el siglo XIX ${ }^{115}$. Este trabajo comienza con un análisis geográfico, histórico y administrativo de la ciudad de oscense, de la vicaría que en ella tenía fundada el arzobispado de Toledo y, por último, de la erección, de la construcción y de los aspectos organizativos de la iglesia de Santa María a través de su cabildo beneficial. Después se examinan las directrices musicales que contienen las Ordenanzas de la iglesia de Santa María

111 DAZA PALACIOS, 2009.

112 BONASTRE I BERTRÁN y GREGORI I CIFRÉ, 2009b, 2 vols.

113 BONASTRE I BERTRÁN y CORTĖS I MIR (coords.), 2009a.

114 GREGORI I CIFRÉ, 2009: 101-105.

115 PÉREZ MANCILLA, 2009. 
de 1590, abordando seguidamente el estudio del coro de los oficios y sus integrantes a lo largo del tiempo. A continuación se hace lo mismo con la capilla de música y se analiza el papel de sus maestros, cantores e instrumentistas, dentro del grupo y en el entorno social, cultural y musical. Con ello se pasa al último capítulo del trabajo, dedicado al repertorio, analizando la formación y continuidad del mismo, su codicología, época, géneros y autores.

En 2009 también aparece el libro de José María Vives titulado Consueta de la Festa o Misterio de Elche $e^{116}$, donde el autor edita la música de este drama litúrgico tomando como fuente principal la Consueta del mismo copiada en 1709. Así, este volumen es uno de los escasos ejemplos de edición de música procedente de un templo sin rango colegial o catedralicio.

Finalmente, el último estudio que trata el tema parroquial es el monográfico de Paulino Capdepón sobre La música en Irún en el siglo XIX: la capilla de la iglesia parroquial de Santa María del Juncal, de $2011^{117}$. Éste era un templo con cabildo de beneficiados, pero que tenía como patrono al ayuntamiento irunés. En cuanto a la música, el trabajo recoge la existencia de un coro de los oficios y de una capilla al menos desde 1645, haciendo un análisis concienzudo de esta última durante el siglo XIX. Además, el autor también dedica un espacio al órgano Cavaillé-Coll construido en Santa María del Juncal en la citada centuria.

\section{CONCLUSIONES}

Este recorrido historiográfico pone al descubierto la profusa actividad musical desarrollada en las iglesias parroquiales españolas a lo largo de los siglos. Además, el artículo demuestra que no son pocos los trabajos con referencias al tema de la música en parroquias, aunque es innegable que muchos de ellos lo han tratado de forma tangencial y como epígrafes o noticias puntuales. Así, llama profundamente la atención que la mayoría de estudios sobre parroquias sean artículos en revistas o capítulos de libros, pero no volúmenes monográficos dedicados a un centro concreto. Además, algunos de los trabajos se realizaron porque las iglesias objeto de estudio ascendieron al rango de parroquia basilical o incluso al catedralicio, pero los datos demuestran que la mayor parte de su historia ostentaron únicamente la categoría de parroquia.

Otra cuestión importante es que casi todas las investigaciones sobre parroquias se han dedicado a los órganos de las mismas, presentando su historia, descripción técnica, organeros o, simplemente, reproduciendo los contratos establecidos para la construcción de los instrumentos; en cualquier caso, estos trabajos demuestran el desarrollo de actividad musical en multitud de templos parroquiales. Por fortuna, han sido cada vez más las publicaciones que también han tratado de los intérpretes, es decir, de los organistas, aunque no de la función de su música en el desarrollo litúrgico.

116 VIVES RAMIRO, 2009.

117 CAPDEPÓN VERDÚ, 2011. 
Frente a la abundancia de estudios sobre órganos, los dedicados a las capillas musicales de parroquias han sido exiguos. Queda claro que casi todas estas iglesias contaron con órgano y que no todas dispusieron de capilla; aún así, la parquedad de trabajos sobre la actividad musical de estos grupos no queda justificada, ya que son abundantes las referencias aparecidas en los trabajos realizados que demuestran cómo las capillas de música no fueron exclusivas de catedrales o colegiatas; muy al contrario, las parroquias que dispusieron de ellas fueron bastantes, aunque es obvio que el número de componentes estuvo supeditado a la disponibilidad económica -obligando en ocasiones a aunar varias plazas en una misma persona- y, cómo no, a las corrientes estilísticas de cada época. Aún así, algunas parroquias llegaron a tener capillas musicales a la altura de colegiatas e incluso de ciertas catedrales menores, todo ello gracias a periodos florecientes de economía local. Prueba del nivel de estos grupos fue que muchos de los maestros de capilla y músicos pasaron directamente a desarrollar su actividad en colegiatas y catedrales tras hacerlo en parroquias. Sin embargo, son realmente escasos los trabajos que han situado una parroquia en el contexto musical del país, relacionándola con iglesias de igual y superior rango. Por tanto, falta establecer los itinerarios musicales de las parroquias entre sí y de éstas con colegiatas y catedrales, tanto a nivel de recursos humanos como en relación a cuestiones sociales, económicas o estéticas.

Todavía más importante es el vacío historiográfico sobre la interpretación del canto llano en las iglesias parroquiales, ya que esta música sí que estuvo presente en la mayor parte de ellas. Así, los trabajos se han centrado en algunos de los templos que contaron con un gran coro para los oficios y misas -regido por un sochantre y al que pertenecían todos los clérigos-, pero no se han dedicado a las iglesias donde el número de intérpretes era menor y que, en ocasiones, se limitaba a los sacerdotes celebrantes. Por tanto, queda claro cómo entre las parroquias hubo: unas que dispusieron de capilla musical y de coro para los oficios; otras sólo de intérpretes para el canto llano; y, un tercer grupo, que no contaron con ninguna de estas dos estructuras. En cualquier caso, resulta evidente que la mayoría de parroquias insertaron la música en sus cultos como un elemento litúrgico más, disponiendo casi todas de órgano y organista y, por supuesto, de clérigos que hacían uso del canto en las celebraciones.

Con el recorrido historiográfico realizado también se demuestra que en las parroquias hubo distintos métodos para financiar los recursos de música, tanto materiales como humanos. Así, en un primer grupo se hallaban las iglesias más importantes que dependían principalmente de sus propios ingresos en concepto de diezmos y primicias, disponiendo por norma general de un cabildo de beneficiados que era quien administraba el centro y, por tanto, era responsable de contratar o fijar el salario de los músicos -con el visto bueno del Ordinario correspondiente-. Otras iglesias, por el contrario, dependían económicamente de sus patronos, que en la mayor parte de ocasiones eran los concejos de las localidades en cuestión y, en menor medida, nobles, ejerciendo en cualquier caso el derecho administrativo musical. Por último, el tercer grupo fue el de las parroquias financiadas con sus propios recursos y administradas normalmente por juntas, en las que estaban representados los clérigos, feligreses y autoridades civiles, pero que, en ocasiones, recibieron el apoyo de los concejos locales para la construcción de órganos o para la inclusión de música en determinadas fiestas religiosas. Además, tampoco fue extraña la financiación de recursos musicales en parroquias gracias a la fundación u obra pía de algún feligrés o clérigo. 
En definitiva, queda claro cómo de los miles de parroquias españolas sólo se ha estudiado un número insignificante de ellas y, aún así, son bastantes los casos en que los aspectos económicos, sociales, estilísticos y de relación con el entorno han sido olvidados. Por ello, esperamos que este artículo facilite e incentive la realización de otros estudios musicológicos en el ámbito parroquial, que permitan obtener una visión de conjunto y explicar el verdadero papel que desempeñaron estos centros en el contexto musical español.

\section{BIBLIOGRAFÍA}

ALEPUZ, Miguel y BENEITO, Carlos, “El órgano de Ribesalbes (Castellón)”, Cabanilles, 1 (Valencia, 1982): 30-31.

ALONSO CLIMENT, Vicente, "Órganos y organistas de Alzira”, Cabanilles, 14-16 (Valencia, 1985): 9-180.

ALONSO TOMÁS, Miguel, "El órgano de la parroquia de San Valero de Valencia”, Cabanilles, 27 (Valencia, 1988): 5-32.

ÁLVAREZ MARTÍNEZ, Rosario y SIEMENS HERNÁNDEZ, Lothar, La música en la sociedad canaria a través de la historia. I-Desde el período aborigen hasta 1600, Madrid, El Museo Canario-COSIMTE, 2005.

ANDRÉS FERRANDIS, Antonio y SANCHÍS ALFONSO, José Ramón, "El órgano de Alaquàs", Cabanilles, 28 (Valencia, 1988): 3-21.

ARAIZ MARTÍNEZ, Andrés, Historia de la música religiosa en España, Barcelona, Editorial Labor, 1942.

AYARRA JARNE, José Enrique, Órganos en la provincia de Sevilla. Inventario y catálogo, Granada, Centro de Documentación Musical de Andalucía, 1998.

BAGÜÉS ERRIONDO, Jon, “Catálogo de los fondos musicales antiguos de Laguardia (Álava)”, Cuadernos de Sección-Música, 2 (San Sebastián, 1985): 157-184.

BALDELLÓ BENOSA, Francisco de Paula, "Órganos y organeros en Barcelona. Siglos XIII-XIX", Anuario Musical, 1 (Barcelona, 1946): 195-237.

BALDELLÓ BENOSA, Francisco de Paula, "Los órganos de la basílica parroquial de Nuestra Señora de los Reyes (Pino), de Barcelona”, Anuario Musical, 4 (Barcelona, 1949): 155-179.

BALDELLÓ BENOSA, Francisco de Paula, “La música en la basílica parroquial de Santa María del Mar, de Barcelona”, Anuario Musical, 17 (Barcelona, 1962): 209-241.

BARRIOS MANZANO, María del Pilar, Historia de la música en Cáceres, 1590-1750, Cáceres, Institución Cultural «El Brocense», 1984.

BERENGUER, Josep Lluis y DÍAZ, Joan Baptista, “Orgue de Callosa d'en Sarrià”, Cabanilles, 17 (Valencia, 1986): 4-10, 23-24.

BERENGUER, Josep Lluis y DÍAZ, Joan Baptista, “Órgano de Santa Bárbara (Rocafort)”, Cabanilles, 24 (Valencia, 1987): 5-8. 
BONASTRE I BERTRÁN, Francesc, "El órgano de Santa María de Montblanc y sus organistas durante los siglos XVII-XVIII”, Anuario Musical, 28-29 (Barcelona, 1973-1974-1976-): 243-267.

BONASTRE I BERTRÁN, Francesc, “L'orgue de Sarreal de 1788”, I Congreso Nacional de Musicología, Zaragoza, Institución «Fernando el Católico» (CSIC), 1981a: 267-275.

BONASTRE I BERTRÁN, Francesc, “Josep Carcoler (†1776): noticia biográfica i compositiva”, Recerca Musicològica, 1 (Bellaterra, 1981b): 113-150.

BONASTRE I BERTRÁN, Francesc, "L'obra de fra Bartolomeu Triay a l'orgue de Torroella de Montgrí [de] 1682”, Anuario Musical, 43 (Barcelona, 1988): 111-119.

BONASTRE I BERTRÁN, Francesc y CORTÈS I MIR, Francesc (coords.), Història crítica de la música catalana, Barcelona, Universitat Autònoma de Barcelona, 2009a.

BONASTRE I BERTRÁN, Francesc y GREGORI I CIFRÉ, Josep Maria, Fons de l'església parroquial de Sant Pere i Sant Pau de Canet de Mar, Barcelona, Generalitat de Catalunya (Departament de Cultura), 2009b, 2 vols.

BRUGUÉS I AGUSTÍ, Lluís, La música a Girona, Girona, Diputació, 2008.

CALAHORRA MARTínEZ, Pedro, "Cien años de la historia del órgano de San Pablo de Zaragoza (1742-1826)”, Anuario Musical, 25 (Barcelona, 1970-1971-): 143-167.

CAMACHO SÁNCHEZ, Pilar, La música y los músicos en la iglesia riojana de Briones: formación de un archivo musical parroquial, Logroño, Universidad de La Rioja, 2002.

CANDEL CRESPO, Francisco, “Órganos de don Matías Salanova en Murcia, 1763-1777”, Cabanilles, 21 (Valencia, 1987): 5-37.

CANDEL CRESPO, Francisco, "Contrato para la construcción del órgano de la iglesia parroquial de San Bartolomé, en Murcia, por Miguel Alcarria. 1817”, Nassarre, 14/1 (Zaragoza, 1998): 251-267.

CANO RÉVORA, María Gloria, "La capilla de música de la iglesia prioral de El Puerto de Santa María durante el siglo XVIII”, Revista de Historia de El Puerto, 20 (El Puerto de Santa María, 1998): 45-64.

CAPDEPÓN VERDÚ, Paulino, La música en Irún en el siglo XIX: la capilla de la iglesia parroquial de Santa María del Juncal, Irún, Ayuntamiento, 2011.

CASARES RODICIO, Emilio et al. (dirs.), Diccionario de la música española e hispanoamericana, Madrid, Sociedad General de Autores y Editores, 1999-2002, 10 vols.

CASTAÑO GARCÍA, Joan, "Capítulos por los que se rige el cargo de maestro de capilla de la iglesia de Santa María de Elche. Año 1700”, Pobladores de Elche, 7 (Elche, 1985): sin paginar.

CASTAÑO GARCÍA, Joan, "La música en la iglesia de Santa María de Elche”, Cabanilles, 18-20 (Valencia, 1986): 13-164.

CEA GALÁN, Andrés y CHÍA TRIGOS, Isabel, Órganos en la provincia de Cádiz. Inventario y catálogo, Granada, Centro de Documentación Musical de Andalucía, 1995.

CEA GALÁN, Andrés y CHÍA TRIGOS, Isabel, Órganos en la provincia de Huelva. Inventario y catálogo, Granada, Centro de Documentación Musical de Andalucía, 1996.

CIVIL CASTELLVÍ, Francesc, El fet musical a les comarques gironines en el lapse de temps 1800-1936, Gerona, Caja de Pensiones para la Vejez y de Ahorros de Cataluña y Baleares, 1970. 
CIVIL CASTELLVÍ, Francesc, "Mestres de la capella de cant i organistes de la parroquia de Sant Esteve de la vila d'Olot, segles XVII i XVIII", II Assemblea d'Estudis sobre el Comtat de Besalú. Actes, Olot, Amics de Besalú i el seu Comtat, 1973: 103-110.

CLASTRIER, Françoise y CANDENDO ZABALA, Óscar, “Órganos franceses en el País Vasco y Navarra (1855-1925)”, Cuadernos de Sección-Música, 7 (San Sebastián, 1994): 145-212.

DAZA PALACIOS, Salvador, Música y sociedad en Sanlúcar de Barrameda (1600-1975), Granada, Centro de Documentación Musical de Andalucía, 2009.

DÍAZ, Joan Baptista, "El órgano de Montesa”, Cabanilles, 22 (Valencia, 1987): 3-6.

DONOSTIA, José Antonio de, Música y músicos en el País Vasco, San Sebastián, Biblioteca Vascongada de Amigos del País, 1951.

DONOSTIA, José Antonio de, “El órgano de Tolosa (Guipúzcoa), del año 1686”, Anuario Musical, 10 (Barcelona, 1955): 121-136.

DOÑATE SEBASTIÁ, José María, “Órgano de Villarreal”, Órganos del País Valenciano, 7 (Valencia, 1980): 13-21.

ELIZONDO IRIARTE, Esteban, La organería romántica en el País Vasco y Navarra (1856-1940), Bilbao, Servicio Editorial de la Universidad del País Vasco, 2002.

ESLAVA Y ELIZONDO, Miguel Hilarión, Lyra Sacro-Hispana. Gran colección de obras de música religiosa compuesta por los más acreditados maestros españoles, tanto antiguos como modernos, Madrid, Martín Salazar, 1852-1860, 10 vols.

ESPARZA AZCONA, Ana Isabel, "Cantorales de la merindad de Estella”, Mito y realidad en la historia de Navarra. Actas del IV Congreso de Historia de Navarra, Pamplona, Sociedad de Estudios Históricos de Navarra, 1998, vol. 2: 399-406.

ESTELRICH I MASSUTTÍ, Pere, MASSOT I MUNTANER, Biel y PARETS Y SERRA, Joan, Apunts sobre el fet musical a Felanitx, Felanitx, Ajuntament, 1987.

FERNÁNDEZ DE LA CUESTA, Ismael, “Los cantos monódicos en el «Misterio de Elche»”, Revista de Musicología, 4/1 (Madrid, 1981): 41-49.

FLAMARIQUE, Pedro María, “Músicos y música en Tafalla”, Cuadernos de Cultura Tafallesa, 8 (Tafalla, 1995): 1-139.

FOS MARTÍ, Josep Lluís, "Nuevas aportaciones a la música suecana del XVII”, Cabanilles, 26 (Valencia, 1988): 11-13.

GALLEGO GALLEGO, Antonio, "Un siglo de música en Valdemoro (1582-1692)”, Revista de Musicología, 1/1-2 (Madrid, 1978): 243-253.

GEMBERO USTÁRROZ, María, "El patronazgo ciudadano en la gestión de la música eclesiástica: la parroquia de San Nicolás de Pamplona (1700-1800)", Nassarre, 14/1 (Zaragoza, 1998): 269-362.

GIMÉNEZ ÚBEDA, Joan Ramón, “Orgues i organistes a Albalat de la Ribera”, Cabanilles, 34-36 (Valencia, 1990): 7-111.

GÓMEZ MUNTANER, María del Carmen, “Tradición y modernidad en el Misterio de Elche”, Monsalvat, 151 (Barcelona, 1987): 9-13. 
GREGORI I CIFRÉ, Josep Maria, “L'orgue de Santa Maria d'Igualada i l'obra restauradora dels orgueners Josep Boscà i Antoni Boscà al segle XVIII”, Butlletí de la Societat Catalana de Musicologia, 1 (Barcelona, 1979): 75-93.

GREGORI I CIFRÉ, Josep Maria, “Els organistes de Santa Maria d'Igualada en el período 1689-1738: documents per a la seva historia", Recerca Musicològica, 1 (Bellaterra, 1981): 95-112.

GREGORI I CIFRÉ, Josep Maria, "Renaixement i Manierisme”, BONASTRE I BERTRÁN, Francesc y CORTÈS I MIR, Francesc (coords.), Història crítica de la música catalana, Barcelona, Universitat Autònoma de Barcelona, 2009: 101-105.

GURBINDO GIL, Beatriz, "Los cantorales de la iglesia parroquial de San Andrés de Villava y otras noticias musicales", Mito y realidad en la historia de Navarra. Actas del IV Congreso de Historia de Navarra, Pamplona, Sociedad de Estudios Históricos de Navarra, 1998, vol. 2: 407-411.

HERAS I TRIAS, Assumpció, "La instauració del magisteri de cant de Sant Pere de Figueres a les primeries del segle XVII”, Recerca Musicològica, 1 (Bellaterra, 1981): 203-212.

JAMBOU, Louis, Evolución del órgano español. Siglos XVI-XVIII, Oviedo, Universidad, 1988, 2 vols.

JIMÉNEZ CAVALLÉ, Pedro, “La música en la Santa Capilla de San Andrés. Notas históricas”, Boletín del Instituto de Estudios Giennenses, 129 (Jaén, 1987): 9-31.

LABEAGA MENDIOLA, Juan Cruz, "La música en la parroquia de Santa María de Viana (Navarra), siglos XVI y XVII”, Príncipe de Viana, 158-159 (Pamplona, 1980): 203-250.

LABEAGA MENDIOLA, Juan Cruz, "Diversiones públicas en las fiestas religiosas [del] siglo XVIII de la parroquia de San Pedro de Viana (Navarra)", Actas del IX Congreso de Estudios Vascos «Antecedentes próximos de la sociedad vasca actual. Siglos XVIII y XIX», San Sebastián, Sociedad de Estudios Vascos, 1984: 452-453.

LABEAGA MENDIOLA, Juan Cruz, "La música en la parroquia de San Pedro de Viana (Navarra)", Cuadernos de Sección-Música, 2 (San Sebastián, 1985): 7-77.

LABEAGA MENDIOLA, Juan Cruz, "Órganos y organistas de Sangüesa (Navarra)”, Revista de Musicología, 9/1 (Madrid, 1986): 57-96.

LABEAGA MENDIOLA, Juan Cruz, "La capilla de música de Santa María de Viana, Navarra (siglos XVI-XIX)”, Príncipe de Viana, 238 (Pamplona, 2006): 389-424.

LLUESMA I ESPANYA, Josep Antoni, "Los órganos de Santa María de Sagunto y el mundo musical de su entorno", Cabanilles, 33 (Valencia, 1990): 3-48.

LÓPEZ-CALO, José, La música en la catedral de Granada en el siglo XVI, Granada, Fundación «Rodríguez Acosta», 1963, 2 vols.

MADOZ IBÁÑEZ, Pascual, Diccionario Geográfico-Estadístico-Histórico de España y sus posesiones de Ultramar, Madrid, Tipografía Madoz y Sagasti, 1845-1850, 16 vols.

MADURELL, Josep Maria, "Documentos para la historia del órgano en España”, Anuario Musical, 2 (Barcelona, 1947): 203-216. 
MADURELL, Josep Maria, "Documentos para la historia de maestros de capilla, infantes de coro, maestros de música y danza y ministriles en Barcelona. Siglos XIV-XVIII”, Anuario Musical, 3 (Barcelona, 1948): 213-234.

MADURELL, Josep Maria, "Documentos para la historia de maestros de capilla, organistas, órganos, organeros, músicos e instrumentos. Siglos XIV-XVIII”, Anuario Musical, 4 (Barcelona, 1949): 193-220.

MADURELL, Josep Maria, "Documentos para la historia de los maestros de capilla, cantores, organistas, órganos y organeros. Siglos XIV-XVIII”, Anuario Musical, 6 (Barcelona, 1951): 205-255.

MADURELL, Josep Maria, "Fundacions litúrgiques a Santa Maria de Mataró", Anuario Musical, 19 (Barcelona, 1964): 11-117.

MARQUÈS I PLANAGUMÀ, Josep Maria, “Organistes i mestres de capella de la Diòcesi de Girona”, Anuario Musical, 54 (Barcelona, 1999): 89-130.

MARTÍNEZ SOLAESA, Adalberto, Órganos en la provincia de Málaga. Catalogación y estudio analítico, Granada, Centro de Documentación Musical de Andalucía, 1997.

MASSIP BONET, Jesús Francesc, "El Misterio de Elche. Sobre las obligaciones del maestro de capilla", Monsalvat, 151 (Barcelona, 1987): 14-18.

MELGARES GUERRERO, José Antonio, El órgano de la iglesia de San José en el complejo conventual de las Carmelitas de Caravaca. Órganos Barrocos de Caravaca, Caravaca de la Cruz, Caja-Murcia, 1989.

MILIÁN MESTRE, Manuel, "Historia del órgano de Santa María la Mayor de Morella (Castellón)”, Anuario Musical, 21 (Barcelona, 1966-1968-): 169-187.

MORENO IZAL, María del Burgo, "Cantorales en la merindad de Tudela”, Mito y realidad en la historia de Navarra. Actas del IV Congreso de Historia de Navarra, Pamplona, Sociedad de Estudios Históricos de Navarra, 1998, vol. 2: 423-430.

MORENO MORENO, Berta, "Felipe Gorriti: maestro de capilla de Tafalla (1859-1867)", Mito y realidad en la historia de Navarra. Actas del IV Congreso de Historia de Navarra, Pamplona, Sociedad de Estudios Históricos de Navarra, 1998, vol. 2: 431-441.

MORENO MORENO, Berta, "La vida musical de Tafalla (Navarra) en la época de Felipe Gorriti (18591867)”, Príncipe de Viana, 238 (Pamplona, 2006): 561-576.

NICOLAU BAUZÁ, Josep, “Órganos de la parroquia de los Santos Juanes”, Cabanilles, 7 (Valencia, 1983): 5-30.

NICOLAU BAUZÁ, Josep, “Un orgue per a la Capella de la Mare de Déu de Gràcia a l'esglèsia de Sant Agustí de Valencia (1503)”, Cabanilles, 17 (Valencia, 1986a): 25-26.

NICOLAU BAUZÁ, Josep, “Un orgue per a la parroquia de Sant Tomàs de Valencia (1489)”, Cabanilles, 17 (Valencia, 1986b): 27-29.

NOGUERA, Antonio, “La capella de Manacor”, La música religiosa en España, 31 (Madrid, 1898): 97-105.

OLMOS I TAMARIT, Vicent y LÓPEZ I QUILES, Antoni, “Órganos y organistas de Catarroja (Valencia)", Cabanilles, 8 (Valencia, 1983): 2-33. 
PALACIOS SANZ, José Ignacio, Órganos y organeros en la provincia de Soria, Soria, Diputación Provincial, 1994.

PARADA Y BARRETO, José, Diccionario técnico, histórico y biográfico de la música, Madrid, Casa Editorial de Bonifacio Eslava, 1868.

PAVIA I SIMÓ, Josep, “La música a la parròquia de Sant Just i Sant Pastor de Barcelona, durant el segle XVII", Anuario Musical, 48 (Barcelona, 1993): 103-142.

PEDRELL SABATÉ, Felipe, Diccionario biográfico y bibliográfico de músicos y escritores de música españoles, portugueses e hispano-americanos, antiguos y modernos. Acopio de datos y documentos para servir a la historia del arte musical en nuestra nación, Barcelona, Tipografía de Víctor Berdós y Feliu, 1897.

PÉREZ-JORGE, Vicente, La música en Onteniente, Valencia, Diputación Provincial, 1979, 3 vols.

PÉREZ MANCILLA, Victoriano José, La música en la iglesia de Santa María de Huéscar hasta el siglo XIX, Tesis Doctoral, Universidad de Granada, 2009.

PINGARRÓN SECO, Fernando, "La música en la parroquia de San Martín de Valencia (ss. XVI-XX)", Cabanilles, 2-3 (Valencia, 1982): 6-86.

PINGARRÓN SECO, Fernando, "Dades sobre un orgue de Nicolau de Salanova a l'esglèsia parroquial de la Santa Creu de Valéncia a primeries del segle XVIII”, Cabanilles, 9 (Valencia, 1984): 8-32.

RAMÍREZ PALACIOS, Antonio y RAMOS SUÁREZ, Manuel Antonio, Catálogo del archivo musical de la parroquia de San Juan Bautista de Marchena (Sevilla), Granada, Centro de Documentación Musical de Andalucía, 2005.

RANCH SALES, Amparo, "Órganos y organistas de la villa de Ayora”, Cabanilles, 4 (Valencia, 1982): 2-35.

RODRÍGUEZ SUSO, Carmen, "La capilla musical de Santiago: una institución peculiar”, La catedral de Santiago. Bilbao, Bilbao, Obispado, 2000: 167-195.

ROS-FÁBREGAS, Emilio, "Historiografía de la música en las catedrales españolas: nacionalismo y positivismo en la investigación musicológica”, Codexxi. Revista de Comunicación Musical, 1 (Barcelona, 1998): 68-135.

ROS PÉREZ, Vicente, "Oposiciones al cargo de organista en Sueca (Valencia) a la muerte de Vicente Hervás (1745)”, I Congreso Nacional de Musicología, Zaragoza, Institución «Fernando el Católico» (CSIC), 1981: 363-364.

ROS PÉREZ, Vicente, "Nuevos documentos sobre órganos del maestrazgo", Cabanilles, 22 (Valencia, 1987): 23-28.

RUIZ JIMÉNEZ, Juan, Organería en la Diócesis de Granada (1492-1625), Granada, Diputación Provincial y Centro de Documentación Musical de Andalucía, 1995.

RUIZ DE LIHORY, José, La música en Valencia. Diccionario biográfico y crítico, Valencia, Establecimiento Tipográfico Domenech, 1903.

RUIZ VERA, José Luis, "Un aspecto ignorado para la historia: la música en la vida local. La capilla de música de la iglesia parroquial de Nuestra Señora de la Asunción y Ángeles de Cabra (Córdoba)", 
ARANDA DONCEL, Juan (coord.), Encuentros de historia local. La Subbética, Córdoba, Adisur, 1990: 247-255.

SALA CAÑELLAS, Vicent, "L'orgue de l'esglèsia parroquial de Sant Pere Apòstol de Novelda", Cabanilles, 9 (Valencia, 1984): 3-7.

SALDONI Y REMENDO, Baltasar, Diccionario biográfico-bibliográfico de efemérides de músicos españoles, Madrid, Imprenta de Antonio Pérez Dubrull, 1868-1881, 4 vols.

SÁNCHEZ HUEDO, Olga, La actividad artístico-musical de Albacete en la segunda mitad del siglo XIX, Albacete, Instituto de Estudios Albacetenses «Don Juan Manuel», 2004.

SÁNCHEZ PORTAS, Javier, «Los órganos de la iglesia de la Merced de Orihuela, siglos XVII-XX», Cabanilles, 25 (Valencia, 1988): 5-21.

SÁNCHEZ REAL, José, "El órgano y los organistas de la Iglesia Mayor de Montblanc", Recerca Musicològica, 3 (Bellaterra, 1983): 81-136.

SERRA SANMIGUEL, Joan y MARTÍ I BONET, Josep Maria, "Orgues i harmònius destruïts durant la Guerra Civil (1936-1939) a les parròquies de la Diòcesi de Barcelona”, Anuario Musical, 57 (Barcelona, 2002): 251-275.

SOLÀ, Fortià, "La música a Catalunya. Aplega de materials per contribuir a sa historia”, Revista Musical Catalana, 136 (Barcelona, 1915): 102-103.

SOLER GARCÍA, José María, "La antigua capilla musical de Santiago de Villena”, Revista del Instituto de Estudios Alicantinos, 2 (Alicante, 1969): 7-36.

SOLER GARCÍA, José María, "El antiguo órgano de la iglesia parroquial de Sax (Alicante)", Cabanilles, 1 (Valencia, 1982): 35-36.

SORRIBES CARCELLER, Serafín, “Órgano de Cinctorres (Castellón), Órganos del País Valenciano, 12 (Valencia, 1980): 2-24.

STEVENSON, Robert, Spanish Cathedral Music in the Golden Age, Berkeley y Los Angeles, University of California Press, 1961.

TEMPERLEY, Nicholas, The Music of the English Parish Church, Cambridge, Cambridge University Press, 1979, 2 vols.

THOMÀS I SABATER, Joan Maria y PARETS Y SERRA, Joan, Breu historia musical de les Illes Balears, Palma de Mallorca, s/e, 1982.

TORRES CAROT, Rafael, "La iglesia, el órgano y la música en Villafamés (Castellón)”, Cabanilles, 12 (Valencia, 1984): 4-10.

TORRES I PETERS, Francesc Xavier, Música i músics a l'Eivissa dels segles XVI, XVII i XVIII, Eivissa, Editorial Mediterrània-Eivissa, 2002.

VILLALMANZO CAMENO, Jesús, "Breve aportación nueva al historial musical de la parroquia de San Martín de Valencia”, Cabanilles, 12 (Valencia, 1984): 11-14, 23.

VILLALMANZO CAMENO, Jesús, La música en la parroquia de los Santos Juanes de Valencia durante el siglo XVIII, Valencia, Generalitat Valenciana, 1992.

VIVES RAMIRO, José María, Consueta de la Festa o Misterio de Elche, Valencia, Ajuntament d'Elx, 2009. 
ZUDAIRE HUARTE, Claudio, "Notas sobre órganos y organistas de Guipúzcoa en el siglo XVII”, Cuadernos de Sección-Música, 2 (San Sebastián, 1985): 79-101.

ZUDAIRE HUARTE, Claudio, "La vida musical en la parroquia navarra de Falces (siglos XVII al XIX)", Revista de Musicología, 10/3 (Madrid, 1987): 843-878.

ZUDAIRE HUARTE, Claudio, "Simón de Artozqui: primer organista de Hernani”, Cuadernos de Sección-Música, 4 (San Sebastián, 1988): 83-103.

ZUDAIRE HUARTE, Claudio, "La organistía de Motrico (s. XVII-XVIII)", Cuadernos de Sección-Música, 5 (San Sebastián, 1991): 9-22.

Recibido: 11/04/2011

Aceptado: 21/02/2013 